\title{
La «política antillana» de la Gran Colombia: interpretación realista
}

\section{The «Antillean politics» of Greater Colombia: a realistic interpretation}

\author{
Rafat Ahmed Ghotme Ghotme \\ Universidad Militar Nueva Granada \\ rafat.ghotme@unimilitar.edu.co |https://orcid.org/0000-0002-6270-4498
}

Recibido: 01 de noviembre de 2019. Aprobado: 10 de septiembre de 2020

DOI: 10.25100/hye.v16i55.10873

Artículo de investigación

¿Cómo citar este artículo? / How to quote this article?

Ghotme, Rafat Ahmed. "La «política antillana» de la Gran Colombia: interpretación realista". Historia y Espacio, vol. 16 n 55 (2020):96-129.

Doi.org/10.25100/hye.v16i55.10873 


\title{
Resumen
}

Este artículo tiene como propósito reelaborar la historia de la «política antillana» de la Gran Colombia apoyándose en los aportes teóricos realistas de las Relaciones Internacionales. Las obras tradicionales, por ejemplo, se equivocan al afirmar que Bolívar tuvo la intención real de liberar Cuba y Puerto Rico, y que esa expedición no se puso en marcha por diversas dificultades internas y externas. Este estudio también se aleja -parcialmente- de las obras revisionistas. Esta escuela afirma que Bolívar no tuvo la intención de llevar a cabo la expedición por temor a despertar la cuestión racial en el Caribe y, por el contrario, usó la amenaza de esta para disuadir a España y forzarla a otorgar el reconocimiento a Colombia. Este estudio acepta que Bolívar le dio prioridad a la estrategia disuasoria, pero por otros motivos realistas: la disparidad de poder entre Colombia y España, así como el temor a una reacción virulenta de las grandes potencias; también se verá que la expedición sí fue considerada como un último recurso y en una etapa tardía, aunque esta posibilidad fue sopesada con otras variables internacionales que difícilmente llegaron a cristalizar.

Palabras clave: Gran Colombia, Bolívar, Santander, Cuba, Puerto Rico, Expedición, Realismo.

\begin{abstract}
The article aims to rework the history of the «Antillean politics» of Colombia, relying on the realist theoretical contributions of International Relations. Traditional works are wrong in stating that Bolívar had the real intention of liberating Cuba and Puerto Rico, and that this expedition was not launched due to various internal and external difficulties. This study also departs - partially - from revisionist works. This school claims that Bolívar did not intend to carry out the expedition for fear of raising the racial issue in the Caribbean and, on the contrary, used the threat of this to dissuade Spain and force it to grant recognition to Colombia. This study accepts that Bolívar gave priority to the deterrence strategy, but for other realist reasons: the disparity of power between Colombia and Spain, as well as the fear of a virulent reaction from the great powers; it will also be seen that the expedition was considered as a last resort and at a late stage, although this possibility was weighed against other international variables that hardly came to fruition.
\end{abstract}

Keywords: Gran Colombia, Bolivar, Santander, Cuba, Puerto Rico, Expedition, Realism 


\section{Introducción}

Este artículo tiene como propósito reelaborar la historia de la «política antillana» de la Gran Colombia apoyándose en los aportes conceptuales y teóricos realistas de las Relaciones Internacionales. La «política antillana» se define en este estudio como una estrategia políticomilitar diseñada por los estadistas colombianos en la década de 1820 con el fin de forzar a España a firmar la paz recurriendo a la amenaza (o implementación real) de una expedición de "bloqueo" -y no necesariamente de "liberación"- contra Cuba y Puerto Rico". Este propósito, sin embargo, nunca llegaría a cristalizar; la amenaza no surtiría ningún efecto, y mucho menos se pondría en marcha la expedición. Si se acepta esta definición, y asimismo se reconstruyen la naturaleza y causas de esa estrategia y su fracaso, podrá notarse que las interpretaciones elaboradas hasta el momento carecen o sobrevaloran diversos elementos que son cruciales para entender la evolución de la política antillana de la Gran Colombia.

Tradicionalmente, los historiadores o internacionalistas colombianos han definido la política antillana de la Gran Colombia como una empresa libertadora que anda a mitad de camino entre una estrategia militar que encaja en el proyecto geopolítico de Bolívar, por un lado, y por otro lado cierto espíritu filantrópico, un sentimiento de hermandad hispanoamericana que profesaba el Libertador hacia sus "hermanos" americanos ${ }^{2}$. Apolinar Díaz-Callejas y Roberto González Arana, en ese sentido, sostienen lo siguiente: "Estos audaces objetivos formaban parte de la estrategia político-militar de Bolívar para la liberación hispanoamericana", objetivos que eran, "en cierta forma, una respuesta a las solicitudes de patriotas antillanos para apoyar la liberación de Cuba y Puerto Rico"3.

Esta última explicación es aceptada por algunos académicos puertorriqueños ${ }^{4}$. Otros historiadores cubanos dan por descontado que Bolívar anhelaba llevar a cabo la expedición, aunque este anhelo se vio truncado por múltiples dificultades internas (falta de recursos, inestabilidad política) y externas (la oposición de Estados Unidos e Inglaterra) ${ }^{5}$. DíazCallejas y González Arana, además de considerar que la empresa antillana fracasó por la oposición de Estados Unidos, creen que la razón principal del fracaso obedecía principalmente a razones de índole interna -la inestabilidad y anarquía política en la Gran

\footnotetext{
${ }^{1}$ En este estudio se hará referencia únicamente a Cuba y Puerto Rico, dejando al margen Santo Domingo. Para este último caso, se recomienda la síntesis elaborada por Germán de la Reza, "El intento de integración de Santo Domingo a la Gran Colombia (1821-1822)", Secuencia, no. 93, (2015), 65-82.

${ }^{2}$ Margarita González, Bolívar y la independencia de Cuba (Bogotá: El Áncora Editores, 1985). Para una visión desde la Historia Patria, ver Roberto Suárez, "Colombia y Cuba, 1825-1826", Repertorio Colombiano, XVIII, no. 4 (1898); y Gabriel Porras Troconis, "Bolívar y la Independencia de Cuba”, Boletín historial, 3 , no. 32 (1917): 1-16.

${ }^{3}$ Apolinar Díaz-Callejas y Roberto González Arana, Colombia y Cuba: del distanciamiento a la cooperación (Bogotá: Ediciones Uninorte, 1998), 6.

${ }^{4}$ Edgardo Pratts, "Simón Bolívar y Puerto Rico: acercamiento a una expedición”, 6 de marzo de 2019, MINH. https://minhpuertorico.org/index.php/noticias/55-noticias/7116-edgardo-pratts-claridad

${ }^{5}$ Emeterio S. Santovenia, Bolívar y las Antillas hispanas (Madrid: Espasa Calpe, 1935); y del mismo autor Armonías y conflictos en torno a Cuba (Méjico: Fondo de Cultura Económica, 1956). Para una visión estructuralista, que incluye la situación política, económica y social de las Antillas y las repúblicas hispanas, ver la excelente síntesis de Francisco Pérez Guzmán, Bolívar y la independencia de Cuba (La Habana: Editorial Letras Cubanas, 1988). La historiadora española María del Rosario Sevilla Soler tiene una visión similar, en su obra Las Antillas y la independencia de la América española (1808-1826) (Sevilla: Escuela de Estudios Hispanoamericanos, 1986), 48-49. En la historiografía colombiana, ver Margarita González, Bolívar y la independencia de Cuba.
} 
Colombia ${ }^{6}$. En esa misma línea, el historiador mexicano Hernán Venegas Delgado, en su juicioso y bien elaborado aporte historiográfico de la expedición antillana desde el punto de vista de lo "militar", sostiene que esta empresa no se puso en marcha básicamente porque Colombia (y su aliado mexicano) no tenían los buques de guerra y de transporte necesarios ${ }^{7}$.

Finalmente, algunas obras que recubren la trayectoria idealista de Bolívar sostienen que la expedición antillana -secundada por algunos expedicionarios entusiastas como Páez o Sucre- no se llevó a cabo por el constante saboteo de sus planes por parte de algunos hombres que traicionaron su ideal libertario, como el general Santander ${ }^{8}$.

Esta y las otras tesis referidas hasta acá han sido demolidas por un conjunto de historiadores cubanos que hacen parte de una tendencia que acá se denominará escuela revisionista. Siguiendo la tradición de Ramiro Guerra y Sánchez, esos autores conciben acertadamente- que la política antillana de Bolívar era una estrategia disuasoria que buscaba "alarmar a Fernando VII y obtener el reconocimiento de la independencia de Colombia, así como para inducir a los Estados Unidos y a Inglaterra a ejercer presión diplomática sobre España en el mismo sentido"9. Cuba y Puerto Rico, de ese modo, eran la moneda de cambio, instrumentos o piezas canjeables que tenía Bolívar como baza para negociar la paz con España.

Leví Marrero, en su historia social y económica de Cuba, reproduce esta tesis, pero al mismo tiempo introduce un matiz: "No hubo en cuanto a la independencia de Cuba sostiene- una conducta consistente por parte de Bolívar"10. Esta falta de consistencia se reflejaba en el doble juego que estaba jugando Bolívar tanto en el plano privado como en el público; si por una parte instruía a los plenipotenciarios de Perú y Colombia que prepararan la expedición en el marco del Congreso de Panamá, por otra parte le manifestaba en privado a Santander que no pusiera en marcha dicha expedición. Según lo planteado por el historiador cubano Leonel Antonio de la Cuesta, esta ambivalencia podía obedecer a la condición "maniaco-depresiva" de Bolívar, lo que lo llevaba a promover o abandonar intempestivamente esa empresa"1; pero más allá de esas consideraciones de "psicología colectiva", para este último autor, sin embargo, Bolívar no tenía en realidad la intención de llevar a cabo una expedición contra las autoridades españolas de Cuba, ya que esta empresa

\footnotetext{
${ }^{6}$ Díaz-Callejas y González Arana, Colombia y Cuba, 16 (a ello agregan "las inesperadas complicaciones de la última etapa de la liberación del Perú y el Alto Perú"). En una excelente síntesis de la historia de las relaciones internacionales de México, Antonia Pi-Suñer Llorens y Agustín Sánchez Andrés, sostienen de forma similar que la expedición colombo-mexicana planeada entre 1825 y 1826 no se puso en marcha por la oposición de Estados Unidos y Gran Bretaña, las dificultades internas en Colombia y México y "las reticencias del Congreso de Panamá” (Una historia de encuentros y desencuentros. México y España en el siglo XIX. México: Secretaría de Relaciones Exteriores, 2001, 37).

${ }^{7}$ Hernán Venegas Delgado, “Los planes colombo-mexicanos de expedición conjunta para la liberación de Cuba (1820-1827)", Caribbean Studies, 36, no., 1 (2008): 3-23; y también su libro La Gran Colombia, México y la independencia de las Antillas Hispanas (1820-1827). Hispanoamericanismo e injerencia extranjera (México: Escuela de Ciencias Sociales-Universidad Autónoma de Coahuila-Editorial Plaza y Valdés, 2010).

${ }^{8}$ Francisco Pidival, Bolívar. Pensamiento precursor del antiimperialismo (Cuba: Ediciones Casa de las Américas, 1977), 227, 245.

${ }^{9}$ Ramiro Guerra y Sánchez, Manual de historia de Cuba: desde su descubrimiento hasta 1868 (La Habana: Instituto Cubano del Libro, Editorial de Ciencias Sociales, 1971), 322. En el mismo sentido, ver el libro de Leví Marrero Artiles, Cuba: Economía y Sociedad, vol. VII (Madrid, Editorial Playor, 1992), 84, 107.

${ }^{10}$ Marrero Artiles, Cuba: Economía y Sociedad, 106.

${ }^{11}$ Leonel Antonio de la Cuesta, "Cuba y Venezuela en los primeros años bolivarianos", Revista Hispano Cubana, no. 31 (2008): 106, 110.
} 
"podría convertirse en un nuevo Haití con sus masacres de blancos y la destrucción del país" 12 .

En resumen, existen dos grandes tendencias en el estudio de la evolución de la política antillana de la Gran Colombia: 1) tendencia clásica, que sostiene que Bolívar sí tenía la intención de llevar a cabo la expedición, pero que esta no se puso en marcha por razones domésticas -inestabilidad política, falta de recursos o una armada débil- o por razones internacionales - oposición de Estados Unidos y Gran Bretaña. 2) Tendencia revisionista, que sostiene que Bolívar no tuvo la intención de llevar a cabo la expedición por razones raciales -evitar el fantasma de una nueva Haití-, pero que sí buscaba amenazar con una invasión de las islas antillanas para obligar a España a un avenimiento de la paz.

\section{Revisionismo revisado}

Este estudio va a retomar y reafirmar la tendencia revisionista, pero adicionando algunos "correctivos". Lo primero que se debe advertir es que la política antillana del gobierno colombiano fue consistente en un sentido: a pesar de las múltiples referencias a una expedición, la prioridad era usar la amenaza de esta para obtener de España el reconocimiento, evitando a toda costa una guerra que efectivamente se podía evitar y que de ninguna manera pretendía poner en marcha por razones puramente idealistas. Tanto Bolívar como Santander reconocían que el nuevo régimen que habían instaurado se encontraba en una posición desventajosa con relación a España, y si bien eran conscientes de que la reconquista española era virtualmente improbable, ese statu quo seguía siendo fuente de un enorme estado de indeterminación y temores mutuos. De acuerdo con Bolívar, por tanto, la estrategia más efectiva para "normalizar" sus recientes conquistas era un avenimiento diplomático, pero sustentado en la amenaza de usar la fuerza. Ahora bien, ¿qué ocurría si esta estratega no rendía frutos?; ¿debían asumir una posición pasiva mientras España aumentaba sus capacidades en las Antillas? La respuesta a estas preguntas implica traer a colación otro "correctivo": si la amenaza no surtía efecto, y solo después de un cálculo muy racional de distintas variables, Bolívar y Santander empezaban a considerar seriamente la idea de una expedición. Esta posibilidad era muy remota e, incluso, cuando se colocaba sobre la mesa, podía parecer que se trataba de un clásico bluff. Sin embargo, es preciso advertir que durante algunas ocasiones (en agosto de 1826 y enero de 1827), Bolívar se mostró receptivo a la posibilidad de poner en marcha una campaña expedicionaria.

¿Qué clase de expedición? Cuando Bolívar y Santander, los dos hombres de Estado que dieron forma a la política antillana, hablaban de una expedición, estos pensaban en varias posibilidades: un "bloqueo" a Cuba -que diera como resultado la destrucción del poderío de España en el Caribe-, una eventual anexión de Puerto Rico como base para apoyar el bloqueo de Cuba y, finalmente, una expedición libertadora.

Cualquiera que fuera la forma que adoptara, ¿cómo y bajo qué condiciones las élites colombianas comenzaron a tomar en serio la puesta en marcha de una expedición? Esta decisión estuvo impulsada básicamente por factores internacionales, aunque secundada por una variable política doméstica: si España no cedía, y Colombia se veía amenazada existencialmente por una invasión realista, una expedición no solo propinaría una derrota irreversible a la corona española, sino que sería útil para sacar de la ociosidad a los militares jubilados, evitando al mismo tiempo que estos se sumaran a las filas de los "anarquistas" al

${ }^{12}$ Leonel Antonio de la Cuesta, "Cuba y Venezuela": 105-106.

100 Historia y Espacio • Vol.16. No. $55 \cdot$ julio-diciembre • pp. 96- 129 • Universidad del Valle • E-ISSN 2357-6448 
interior de la República. De cualquier modo, la expedición, para que fuera una realidad, también tenía que esperar que soplaran vientos internacionales favorables: un cambio en las capacidades relativas de poder y en los intereses de las grandes potencias.

Finalmente, el presente estudio no comparte la tesis revisionista según la cual Bolívar no quiso libertar las islas antillanas por razones de índole racial -esto es, un supuesto temor a que la expedición diera paso, como en Haití, a la instauración de una pardocracia. Es cierto que Bolívar tenía una visión jerárquica y racializada de la sociedad, pero ello no implica que el fantasma de Haití fuera asumido de esa forma por Bolívar y que el temor a instaurar una pardocracia le hubiese impedido llevar a cabo la empresa antillana. En realidad, como se verá más adelante, el fantasma de Haití estaba relacionado con otros tipos de consideraciones: el temor a una reacción airada de Gran Bretaña y Francia, quienes sí temían al "despertar" de la cuestión racial. Estados Unidos tenía ese mismo temor, pero la oposición de esta potencia no apareció en los cálculos de Bolívar sino hasta más o menos fines de 1826 o inicios de 1827.

\section{Naturaleza y causas de la política antillana}

Bolívar, como se verá más adelante, se figuraba todo un mundo de fantasías libertadoras y, de vez en cuando, estas se materializaban en una serie de promesas vagas hechas a los más entusiastas partidarios de la expedición. Sin embargo, cuando llegaba la hora decisiva de moldear los contornos de la política antillana, le imprimía un sello realista muy agudo ${ }^{13}$. En ese sentido Bolívar, como cualquier otro estadista pragmático, definía el interés "nacional" de Colombia dando prioridad a -o haciéndolo coincidir con- el objetivo de la supervivencia; de acuerdo a la tradición realista de las Relaciones Internacionales, la política internacional trata de Estados que adoptan estrategias para sobrevivir -o expandir su poder, riqueza y valores desde que estos últimos objetivos no pongan en riesgo su supervivencia-, tomando en consideración la posición de poder que ocupan esos Estados con relación a otros, así como múltiples variables "domésticas” que impulsan sus conductas ${ }^{14}$.

La política antillana formulada por Bolívar y delineada meticulosamente por el general Santander cumplía en términos generales con estos dictados de Realpolitik. Esta política constaba de dos fases. La primera, definida como una estrategia disuasoria que buscaba al máximo evitar una aventura en el Caribe, era la base inamovible del conjunto: las islas de Cuba y Puerto Rico se convirtieron en una carta estratégica reservada para flirtear con amenazas de una invasión libertadora, pero cuyo fin real no era liberar esas islas sino usar esa amenaza para forzar a España a la firma de la paz; y la segunda, consistente en poner en práctica la expedición (como se proyectó una vez en agosto de 1826 y en otra ocasión en enero de 1827), solía aparecer como un último recurso "coercitivo" que, en todo caso, debía ser sopesado con múltiples variables internacionales e internas ${ }^{15}$.

\footnotetext{
13 El término "realista" que se usa en este estudio hace parte de la tradición teórica de las Relaciones Internacionales (también llamada Realpolitik), y no debe ser confundido con el término realista (en este estudio en cursiva), usado para designar a los partidarios de la monarquía española durante la era de las guerras independentistas.

${ }^{14}$ Para un balance, ver Norrin Ripsman, Jeffrey W. Taliaferro, y Steven E. Lobell, Neoclassical Realist Theory of International Politics (New York: Oxford University Press, 2016).

${ }^{15}$ El término diplomacia disuasoria implica la amenaza del uso de la fuerza por parte de un Estado para prevenir que otro altere el statu quo; la "amenaza" es parte crucial de esta estrategia, ya que si no se hace explícita, la acción simplemente puede ser vista como una estrategia defensiva. En cambio, el término diplomacia coercitiva
} 
¿Cómo llegó el gobierno colombiano a delinear esa estrategia? Existen dos variables realistas clave. La primera está relacionada con la balanza de poder militar entre Colombia y España. Las élites republicanas, más preocupadas por su seguridad en la frontera sur, y mientras no vieran en el horizonte una amenaza existencial en el flanco norte, no tenían motivos para emprender una campaña contra las fuerzas monarquistas apostadas en Cuba sin exponer seriamente sus conquistas continentales. Como dijo el general Santander:

“... sobre la expedición a Cuba o Puerto Rico no hay que hablar por ahora: primero, porque estando expuestos a ser invadidos en nuestra casa es locura ir a buscar fortuna a país donde creyéndose que hay jamones no hay ni estacas; segundo, porque el Perú demanda con más urgencia y necesidad auxilios que nos aseguren por el sur; tercero, porque no tengo recursos para expediciones..."16

Tanto Bolívar como Santander creían que una expedición en las Antillas debía contar, como mínimo, con una Armada equiparable a la española. Con ese sentido de realismo tan agudo le dijo Bolívar a Santander: “...yo prefiero ir a Méjico que a la Habana...Sólo en el último caso los arrostraremos todos y aun iremos a España" ${ }^{17}$. En otras palabras, era preferible hacer frente, debilitar y desmoralizar las fuerzas realistas en el continente, antes que sumergirse en una expedición incierta.

El Libertador, asimismo, no tenía ningún motivo para iniciar una confrontación innecesaria si no percibía una amenaza existencial. La coyuntura de 1823 en España, enfrascada en una confrontación entre liberales y monarquistas, le hizo pensar que Gran Bretaña se iba a apoderar de Cuba y Puerto Rico en compensación por su apoyo a las fuerzas liberales; y como Inglaterra también se oponía a las maquinaciones absolutistas en América, concluyó que España ya no tenía una probabilidad seria de reconquistar sus antiguas colonias: "Yo pienso que ya la España estará ocupada por sus enemigos, y lo mismo la Habana y Puerto Rico con el nombre de compensación...Por consiguiente sería una demencia suma comprometer nosotros en el día la suerte de nuestras armas ni aun con esperanzas vehementes del triunfo" 18 .

Este último aspecto nos remite a la segunda variable realista: la geopolítica internacional. Bolívar y algunos de sus más cercanos colaboradores -como Santander- se rehusaban a emprender una expedición contra las Antillas españolas porque no querían provocar represalias de las grandes potencias como Gran Bretaña o Francia.

implica el uso limitado de la fuerza (o incluso su amenaza) para revertir una acción tomada por un Estado que alteró el statu quo. Ver: Michael Mazzar y James Goodby, "Redefining the Role of Deterrence”, en Deterrence: Its Past and Future, eds. George Shultz, Sidney Drell y James Goodby (Stanford: Hoover Institution Press, 2011), 47-97; Robert Art y Patrick Cronin, The United States and Coercive Diplomacy (Washington: United States Institute of Peace Press, 2003); Jack Levy, "Deterrence and Coercive Diplomacy: The Contributions of Alexander George", Political Psychology, Vol. 29, No, 4 (2008): 537-552.

${ }^{16}$ Esas palabras, transmitidas a Páez, recogen la esencia de un encuentro que sostuvo Santander con los rebeldes cubanos en Bogotá, en Santander a Páez, Bogotá, 22 de febrero de 1824, Archivo Santander, vol. XI, 315 -316.

${ }^{17}$ Bolívar a Santander, Chuquisaca, 11 de noviembre de 1825, en Archivo Santander, vol. XIII, 289.

${ }^{18}$ Bolívar a Riva Agüero, Guayaquil, 13 de abril de 1823 (inserto en Bolívar a Santander, Guayaquil, 15 de abril de 1823), en Archivo Santander, vol. IX, 324-325. Riva Agüero era uno de los presidentes (republicanos) del Perú que gobernaba desde el exilio en Trujillo, mientras que el Marqués de Torre Tagle, elegido por un Congreso realista, fue nombrado presidente en Lima.

102 Historia y Espacio • Vol.16. No. $55 \cdot$ julio-diciembre • pp. 96- $129 \bullet$ Universidad del Valle • E-ISSN 2357-6448 
Después de recibir múltiples peticiones para llevar a cabo una expedición libertadora por parte de los rebeldes antillanos, así como de Páez o Sucre, Bolívar le advirtió a Santander en diciembre de 1824: "Más cuenta nos tiene la paz que libertar esas dos islas...La Habana independiente nos daría mucho que hacer, la amenaza [de invadirlas y libertarlas] nos valdrá más que la insurrección. Yo tengo mi política" ${ }^{19}$. ¿Cuál era su política? Pocos meses después hizo más explícito su pensamiento:

"No se olvide Vd. jamás de las tres advertencias políticas que me he atrevido a hacerle: primera, que no nos conviene admitir en la liga al Río de la Plata; segunda, a los Estados Unidos de América, y tercera no libertar a La Habana. Estos tres puntos me parecen de la mayor importancia, pues creo que nuestra liga puede mantenerse perfectamente sin tocar a los extremos del Sur y del Norte: y sin el establecimiento de una nueva república de Haití. Los españoles, para nosotros, ya no son peligrosos, en tanto que los ingleses lo son mucho, porque son omnipotentes; y por lo mismo, terribles." 20

Como se ve, Bolívar prefería no llevar a cabo una expedición sobre Cuba porque básicamente quería evitar una disputa innecesaria con Inglaterra (y Francia) ${ }^{21}$. ¿Cómo encaja la analogía con Haití en esta historia? Haití, hasta ese entonces, no era reconocida por ninguna potencia europea y, de hecho, aún estaba sometida a la incertidumbre de una operación de reconquista por parte de su antiguo amo imperial -esto es, Francia. Talleyrand, el ministro de Asuntos Exteriores francés, había firmado un acuerdo secreto con Gran Bretaña en el Congreso de Viena donde le prometía a esta última potencia el acceso a los puertos haitianos en caso de que Francia recolonizara su antigua colonia ${ }^{22}$. La analogía de Haití con Cuba, pues, se remite precisamente al temor de un bloqueo, aislamiento o reacción virulenta por parte de Inglaterra, que tenía intereses geopolíticos en las Antillas ${ }^{23}$.

Esas consideraciones geopolíticas estaban directamente relacionadas con la cuestión racial. El ministro colombiano en Washington, José María Salazar, era plenamente consciente de ello: una invasión a Cuba, decía, "inquietaría a la Inglaterra y a la Francia, que tienen esclavos en sus colonias" ${ }^{24}$. Cuando el general Santander estaba planificando a

\footnotetext{
${ }^{19}$ Bolívar a Santander, Lima, 20 de diciembre de 1824, en Obras Completas, II (versión digital recuperada de: http://www.archivodellibertador.gob.ve/escritos/inicio.php).

${ }^{20}$ Bolívar a Santander, Arequipa, 20 de mayo de 1825, en Archivo Santander, vol. XII, 371.

${ }^{21}$ Cfr. Bolívar a Riva Agüero, Guayaquil el 13 de abril de 1823, Archivo Santander, vol. IX, 324-325. Del general Santander, quien temía más a Francia en 1823, ver "Substance of a Conference between Charles Todd, Confidential Agent of the United States to Colombia, and Francisco de Paula Santander", 16 de junio de 1823 , en William Manning, Diplomatic correspondence of the United States concerning the independence of the Latin-American nations (New York: Oxford University Press, Dept. of State, 1925), II, 1.262 (en adelante D.C.I.); para una visión de los intereses franceses en las Antillas, ver la obra citada de Hernán Venegas Delgado, La Gran Colombia, México y la independencia de las Antillas Hispanas, especialmente el capítulo 4.

${ }_{22}$ François Blancpain, Un Siècle de Relations Financières entre Haïti et La France (1825-1922) (Paris, Montréal: Budapest L’Harmattan 2001), 43.

${ }^{23}$ Cfr. Bolívar a Riva Agüero, Guayaquil, 13 de abril de 1823, Archivo Santander, vol. IX, 324-325.

${ }^{24}$ Estas palabras recogen la esencia de un encuentro que sostuvo Salazar con el revolucionario guayaquileño Vicente Rocafuerte a mediados de 1823. Salazar, junto al Cónsul General colombiano, Leandro Palacios, tuvieron ese encuentro a instancias de los rebeldes cubanos exiliados en Estados Unidos, quienes solicitaron su apoyo para emprender una expedición independentista, en "Rocafuerte y quince años de Historia de la República del Ecuador”, Prólogo y notas de Neptalí Zúñiga, vol. XIV (Quito: Edición del Gobierno del Ecuador. Homenaje a don Vicente Rocafuerte en el primer centenario de su muerte, 1947), 195.
} 
mediados de 1825 una eventual expedición conjunta con México -como se verá más adelante-, primero quiso conocer cuál sería la reacción británica; el Encargado colombiano en Londres, Manuel José Hurtado, sondeó la opinión de Canning, y este respondió, el 24 de noviembre, con una negativa fulminante. Su respuesta contenía efectivamente una referencia explícita a la cuestión racial: Inglaterra, dijo Canning, no permitiría que se llevase a cabo una expedición, por temor a una "revuelta de negros" en el Gran Caribe ${ }^{25}$. Resignados, en el gobierno colombiano desistieron de esa idea por "la mayor deferencia y consideración hacia el gabinete de San James"26.

Para resumir, las élites colombianas creían que las islas antillanas eran presas de los intereses de las potencias europeas, quienes permanentemente buscaban compensar eventuales desequilibrios políticos y raciales a lo largo de sus posesiones mundiales. En ese sentido, preferían no granjearse la enemistad de rivales mucho más poderosos.

Bolívar, ¿estaba disuadido por el mismo temor racial? Durante la campaña libertadora y la instauración del régimen republicano, el Libertador veía por todas partes el fantasma de la pardocracia, que él mismo caracterizaba como un sistema dominado por una supuesta ira racial de los negros que desencadenarían su furia en una masiva masacre de blancos acompañada por el arrebato de sus propiedades ${ }^{27}$. Sin embargo, si se le da crédito a los apuntes biográficos de José Antonio Páez, también es cierto que Bolívar, una vez desembarcado en Cuba, llegaría con la misión de liberar a los negros de la isla, y después de ello incorporarlos al ejército libertador e instaurar su propia visión de una sociedad liberal, jerárquica y racializada (justamente para prevenir la instauración de una pardocracia) ${ }^{28}$.

No existen razones para pensar, por tanto, que la expedición antillana se viera paralizada por el fantasma de la pardocracia, sino, más bien, por el poder "moral" de los blancos esclavistas que dominaban la isla:

"Yo considero a la Francia y al Continente con respecto a la Inglaterra, como a Colombia con respecto a Santo Domingo. Examine usted esta comparación y la encontrará muy exacta. Jamás podríamos los Continentes hacer la guerra a aquellas islas a causa de sus opiniones y del poder moral que tienen sobre sus oponentes ${ }^{29}$."

En síntesis, Bolívar no tenía incentivos para emprender una expedición libertadora enfrentándose a tantos obstáculos: el poder "moral" de los realistas cubanos, la ventaja militar española y la oposición británica o francesa a una política que iba en detrimento del statu quo colonial en el Caribe.

Todas estas razones, sin embargo, no deben hacer creer que las élites colombianas hubiesen relegado a un campo marginal la idea de llevar a cabo alguna operación diplomática

\footnotetext{
${ }^{25}$ Este cruce de correspondencia aparece impreso en el Hansard's Parliamentary Debates, vol. XXIV (London: T.C. Hansard, 1830), 1019-1023 (versión digital recuperada de: https://babel.hathitrust.org/cgi/pt?id=osu.32435072655376; view=1up;seq=7).

${ }^{26}$ José Manuel Restrepo, Historia de la revolución, IV, 253; y Manuel José Hurtado a Canning, Londres, 24 de diciembre de 1825, en Hansard's Parliamentary Debates, vol. XXIV, 1023.

27 Para un balance, ver Aline Helg, "Simón Bolívar's Republic: a bulwark against the "Tyranny" of the Majority”, Revista de Sociologia e Política, 20, no. 42 (2012): 21-37.

${ }^{28}$ Páez, Memorias del general José Antonio Páez: autobiografía (Madrid: Editorial América, 1916), $453-454$. Una pardocracia, según Bolívar, sería como repetir la experiencia de "ese tremendo monstruo que ha devorado a la isla de Santo Domingo" - haciendo alusión a la ocupación de Santo Domingo por parte de Haití en 1822-, en "Simón Bolívar: un pensamiento sobre el Congreso de Panamá, Lima, Febrero de 1826".

${ }^{29}$ Bolívar a Santander, Potosí, 21 de octubre de 1825, Archivo Santander, XIII, 243.
} 
o militar contra la Cuba realista; de hecho, la amenaza de bloquear, invadir o liberar las islas antillanas era el quid pro quo, la moneda de cambio, para forzar a la corona española a firmar la paz:
"Me parecía bien que el gobierno de Colombia, por los medios que juzgase a propósito, intimase a la España que si en tanto tiempo no reconocía la independencia de Colombia y hacía la paz, estas mismas tropas irían inmediatamente a La Habana y Puerto Rico...Este negocio bien conducido puede producir un grande efecto. Más cuenta nos tiene la paz que libertar esas dos islas...La Habana independiente nos daría mucho que hacer, la amenaza [de invadirlas y libertarlas] nos valdrá más que la insurrección. Yo tengo mi política." 30

Pocos meses después, una vez que sus colaboradores en Perú y Colombia anunciaron la convocatoria del Congreso Anfictiónico, que entre otros objetivos tenía la misión de decidir una expedición a las Antillas españolas, le advirtió a Santander en privado:

"Con respecto a La Habana nos conviene decir a España, que si no hace la paz, pronto estará privada de sus dos grandes islas. Ya he dicho a usted antes esto mismo; y lo repito por si acaso no ha llegado a manos de usted mi carta. El general Sucre tiene muchas ganas de que se verifique la expedición, pero yo no he podido verlo aún para explicarle mis ideas." 31

Sin embargo, Bolívar, a partir de mediados de 1826, comenzó a pensar seriamente en la posibilidad de emprender una operación militar contra las autoridades españolas de Cuba y Puerto Rico. En agosto de ese año, aprovechando los avances realizados por Santander, quien había forjado una alianza con México para "bloquear" Cuba y tomar momentáneamente la isla de Puerto Rico, Bolívar esperaba ampliar este frente en el Congreso de Panamá y promover personalmente una expedición que debía dar como resultado la "toma" de Cuba y Puerto Rico. Esta iniciativa no llego a materializarse, pero una vez más, en enero de 1827 , ideó otro plan para "emancipar" las islas, otro plan que terminaría archivado para no volver a pensar en expediciones nunca más ${ }^{32}$.

Con estas iniciativas, tanto Santander como Bolívar buscaban inicialmente reforzar la estrategia disuasoria, un esfuerzo gigantesco que buscaba hacer más creíble el nivel de amenaza. Pero debido a que sus ofertas de paz no eran escuchadas en Madrid y, por el contrario, la corona española hacía más ostensible su actitud hostil hacia Colombia, Bolívar se decantó momentáneamente por la segunda fase de la estrategia, es decir, una expedición de "bloqueo" o "liberación".

Aunque esta última posibilidad era remota, fue ciertamente tardía y terminó siendo refrenada, el hecho de haberla considerado amerita indagar qué factores confluyeron en torno a esta posibilidad y, del mismo modo, conocer qué impidió su ejecución. La idea de una expedición (bloqueo, anexión o liberación) pasaba a ser una opción real para las élites colombianas solo si se cumplían algunas condiciones, aunque no necesariamente de manera simultánea: en primer lugar, que resurgiera una amenaza existencial de reconquista; en

\footnotetext{
${ }^{30}$ Bolívar a Santander, Lima, 20 de diciembre de 1824, en Obras Completas, II (versión digital recuperada de: http://www.archivodellibertador.gob.ve/escritos/inicio.php).

${ }^{31}$ Bolívar a Santander, Arequipa, 20 de mayo de 1825, en Archivo Santander, vol. XII, 371.

${ }^{32}$ Ver la última sección.
} 
segundo lugar, que existiera una alianza con otras repúblicas hispanoamericanas; y en tercer lugar, que se alinearan las fuerzas en Europa a favor de Colombia. Y, como se verá más adelante, esas condiciones, difícilmente, llegaban a cristalizar.

La diplomacia disuasoria ideada por Bolívar, de ese modo, comenzó a conjugarse con la idea de una expedición articulada con una compleja trama de alianzas, aprestos militares y circunstancias internacionales captadas y desarrolladas virtualmente por Santander, como se verá enseguida.

\section{Evolución de la diplomacia disuasoria}

Aparte de la estrategia disuasoria, las élites criollas pusieron en marcha una campaña de aniquilación del poder español en el Caribe recurriendo a otros métodos coercitivos; el más conocido fue la actividad de corso decretada por el gobierno colombiano en 1817 y reforzada en 1822; otro, más clandestino e indirecto, fue la subversión de las islas a través del apoyo a los criollos rebeldes cubanos ${ }^{33}$.

Sin embargo, el aspecto central de la política antillana de Bolívar, como se ya se dijo, era la estrategia disuasoria. Esta cristalizó después de los triunfos republicanos de 1819-1820. Aprovechando el respiro que le daba la suspensión de hostilidades ${ }^{34}$, en enero de 1821 Bolívar decide enviar a España una comisión diplomática encabezada por José Revenga y José Tiburcio Echeverría, con el fin de negociar una paz definitiva con las Cortes españolas. Los comisionados colombianos debían obtener de España el reconocimiento de los "territorios liberados" - esto es, Nueva Granada, Venezuela y Quito- a cambio de un cese definitivo de hostilidades y la regularización de las relaciones a través de convenios comerciales equilibrados. En caso de que las Cortes no aceptaran esas condiciones, Bolívar estaba dispuesto a ceder Quito, Panamá y los "demás territorios que no alcanzaren la paz e independencia por los mismos medios que Colombia" ${ }^{35}$. Entre estos últimos territorios que

\footnotetext{
${ }^{33}$ Estas dos actividades no se van a desarrollar en el presente artículo. Para una referencia sobre las actividades de corso, ver José Rafael Fortique, El corso venezolano y las misiones de Irving y de Perry en Angostura (Maracaibo, Editorial Universitaria de la Universidad del Zulia, 1968). Para un balance más reciente, ver Hernán Venegas Delgado, "Los planes colombo-mexicanos de expedición conjunta para la Liberación de Cuba (18201827)", Caribbean Studies, 36, no., 1 (2008): 3-23. Sobre el apoyo a los rebeldes cubanos, ver “José Fernández de Madrid y su obra en Cuba" (La Habana: Publicaciones del Archivo Nacional de Cuba, 1962); y Julio Le Riverend, "José Fernández de Madrid en Cuba: su obra", Cuba-Colombia, una historia común (Bogotá, Editorial Universidad Nacional, 1995), 59 y ss.; Julián Vivanco, José Antonio Miralla. Precursor de la Independencia de Cuba (La Habana: Editorial "El Sol”, 1958); Eduardo Torres-Cuevas, "De la Ilustración reformista al reformismo liberal”, Historia de Cuba. La Colonia. Evolución socioeconómica y formación nacional. De los orígenes hasta 1867 (La Habana, Editora Política, 1994), 330; y Roque E. Garrigó, Historia documentada de la conspiración de los Soles y Rayos de Bolívar, 2 tomos (La Habana: Imprenta "El Siglo XX", 1929); entre las mejores síntesis sobre esta historia se encuentra la de Francisco Pérez Guzmán, "Cuba bolivariana”, Revista de la Biblioteca Nacional José Martí, Año 74, XXV, no. 3 (1983): 5-30; y Roque Garrigó, Historia documentada. Ver también la obra de Renée Méndez Capote, 4 conspiraciones (La Habana: Gente Nueva, 1972); y Emilio Roig de Leuchsenring, Bolívar, el Congreso Interamericano de Panamá en 1826, y la independencia de Cuba y Puerto Rico", (La Habana: Oficina del Historiador de la Ciudad, 1956).

${ }^{34}$ La suspensión de hostilidades se establece tras la firma de un armisticio en noviembre de 1820 con el general realista Pablo Morillo.

35 "Instrucciones a que deben arreglarse los señores José Rafael Revenga, Secretario de Estado, de Relaciones Exteriores y Hacienda y el Doctor Tiburcio Echeverría, en la misión que con esta fecha son destinados cerca de España”, Bogotá, 24 de enero de 1821, Archivo General de la Nación, Fondo Ministerio de Relaciones Exteriores, Archivo Diplomático y Consular, No. 411.
}

106 Historia y Espacio • Vol.16. No. 55 julio-diciembre • pp. 96- $129 \bullet$ Universidad del Valle • E-ISSN 2357-6448 
no habían alcanzado la independencia por las armas, y que Bolívar prometía dejar en paz, se encontraban las Antillas españolas.

Tanto el gobierno español, en ese entonces una monarquía constitucional que supuestamente sería más favorable hacia los rebeldes hispanoamericanos, así como los generales españoles esparcidos en Suramérica, rechazaron la oferta de paz $^{36}$. El armisticio se rompería rápidamente con la irrupción de tropas colombianas en los reductos españoles de Venezuela (Maracaibo), continuaría en Ecuador (Pichincha), en el sur de la Nueva Granada (Bomboná), y se prolongaría hasta que el ejército insurgente le arrancó a los realistas su última posesión en Venezuela (Puerto Cabello) en noviembre de 1823. Después de esas batallas, el inmenso territorio de la Gran Colombia comenzó a disfrutar de un relativamente importante periodo de estabilidad y paz internacionales, aunque Bolívar creía que su gozo dependía de una ofensiva masiva contra las tropas realistas en Perú, como en efecto se verificaría ${ }^{37}$.

Bolívar se consagró de lleno a la guerra en el Perú. Ello, a su vez, implicaba evitar una contienda marítima con España que podía derivar en un gasto innecesario de hombres y recursos que podía poner en peligro sus conquistas territoriales en el continente. A diferencia de Perú y el Alto Perú, que eran dos bases contiguas desde donde las autoridades realistas podían emprender una operación de reconquista a través de la frontera sur, Bolívar creía que España no tenía la capacidad para poner en marcha desde Cuba una empresa semejante sobre las costas colombianas. Además, España estaba atravesando una crisis interna que derivó en la invasión de las fuerzas monarquistas francesas, una situación que, según Bolívar, tendería a disminuir sus fuerzas o la llevaría a perder sus posesiones antillanas como consecuencia de las rivalidades europeas. Para Bolívar, poco importaba incluso si Cuba cambiaba su status colonial a favor de alguna potencia europea, si ello alejaba la posibilidad de una guerra y por el contrario acercaba a la paz con España. Como le dijo al presidente peruano Riva Agüero:

"Por los papeles públicos verá usted que los ingleses iban a tomar la Habana y Puerto Rico, y que los aliados iban a entrar en España. Estos sucesos deben mudar la faz de los negocios públicos en uno y otro mundo. Yo pienso que ya la España estará ocupada por sus enemigos, y lo mismo la Habana y Puerto Rico con el nombre de compensación. La Inglaterra no aprobando la conducta de los aliados, y no habiendo España para ellos, reconocerá nuestra independencia y aún hará mucho más. Me parece que todo está ya decidido en favor de la América. Por consiguiente sería una demencia suma comprometer nosotros en el día la suerte de nuestras armas ni aun con esperanzas vehementes del triunfo. Mientras vemos el giro que toma la Europa y la Inglaterra es esta crisis vital, no debemos dar un paso que no esté marcado con una seguridad infinita. Nuestros negocios se están desarrollando en el gabinete de Londres y los campos de la Península. Una victoria más no aumentará nuestro peso

\footnotetext{
${ }^{36}$ Para un balance, ver Pedro Antonio Zubieta, Apuntaciones sobre las primeras misiones diplomáticas de Colombia (Bogotá: Imprenta Nacional, 1924), 335 y ss.

37 Sobre este punto, ver Bolívar a Santander, Guayaquil, 14 de febrero y 12 de marzo de 1823, en Archivo Santander, vol. IX, 247, 284-285; y Bolívar a Santander, Guayaquil, 13 de marzo de 1823, Obras Completas (versión digital recuperada de: http://www.archivodellibertador.gob.ve/escritos/inicio.php).
} 
o volúmen, y la pérdida de la capital de Lima quita el prestigio de la independencia del Perú." 38

Bolívar, por tanto, no reflejó ninguna intención real de emprender una operación contra España en el Caribe (por lo menos no hasta mediados de 1826). Para él, España era incapaz de emprender una operación de reconquista por sí sola desde sus posesiones antillanas -y de hecho no lo llegó a creer en los años críticos de 1823 a 1825, cuando todos en Colombia presumían que lo haría con la ayuda de Francia; esta última posibilidad quedó descartada desde el momento en que Gran Bretaña decidió oponer su poderío naval a una eventual alianza que pudiera concertar España con los miembros de la Santa Alianza ${ }^{39}$. Creyendo que esas condiciones internacionales lo favorecían, el gobierno colombiano continuó su ofensiva diplomática en Londres y París, instruyendo a sus agentes diplomáticos para que aprovecharan "cualquier coyuntura en España para negociar aunque sea un largo $\operatorname{armisticio"} "$. $^{\text {arm }}$

\section{Santander y los contornos militares de la estrategia disuasoria}

La presencia realista en las Antillas, sin embargo, seguía siendo una fuente de amenaza constante; mientras que España no reconociese la independencia de su antigua colonia, las élites republicanas en Colombia vivirían con la incertidumbre de una invasión o de interminables tramas conspirativas fraguadas en Cuba. De las Antillas españolas, de hecho, llegaban frecuentemente rumores de una expedición de reconquista conformada por poderosos buques de guerra, y esto, por supuesto, mantenía encendida las alarmas en Colombia.

Desde una etapa tan temprana como 1822, el general Santander, como encargado del poder ejecutivo, recibía notificaciones de las autoridades locales en Venezuela, Panamá, Cartagena e incluso de sus agentes en Estados Unidos y Europa sobre la situación militar en España y el Caribe, y adjuntas a estas venían consejos para que emprendiera una operación contra Cuba y Puerto Rico. Uno de ellos, el general Montilla (gobernador de la provincia de Santa Marta y posteriormente del Zulia), le decía lo siguiente: "En La Habana se aglomeran fuerzas y con los batallones que iban llegando de México había ya un número disponible. ¡Cuidado con el Istmo!" 41 . En otra ocasión, le llegó una carta de Antonio José de Sucre donde le decía: "La noticia de Puerto Rico se ha corrido aquí; pero no se tiene ningún dato que la haga cierta. Sería muy útil despojar a los españoles de ese punto de apoyo por sus operaciones hostiles en cualquiera evento contra la pobre Venezuela"42.

Gracias en gran medida a esos informes, y gracias también a la asfixiante situación fiscal a la que estaba sometida Colombia por el constante estado de guerra con España,

\footnotetext{
38 Bolívar a Riva Agüero, Guayaquil, 13 de abril de 1823 (inserto en Bolívar a Santander, Guayaquil, 15 de abril de 1823), en Archivo Santander, vol. IX, 324-325. Riva Agüero era uno de los presidentes (republicanos) del Perú que gobernaba desde el exilio en Trujillo, mientras que el Marqués de Torre Tagle, elegido por un Congreso realista, fue nombrado presidente en Lima.

${ }^{39}$ Ver, en ese sentido, Bolívar a Santander, Chuquisaca, 12 de diciembre de 1825 (versión digital recuperada de: http://www.archivodellibertador.gob.ve/escritos/buscador/spip.php?article5076)

${ }^{40}$ Santander a Bolívar, Bogotá, 21 de mayo de 1823, en Archivo Santander, vol. X, 165.

${ }^{41}$ Mariano Montilla a Santander, Santa Marta, 31 de julio de 1822, en Archivo Santander, VIII, 334; ver también las cartas enviadas desde Santa Marta, 30 de octubre de 1822 y 10 de noviembre de 1822; y Cartagena, 11 de septiembre y 10 de noviembre de 1822, Archivo Santander, vol. XI, 31, 128, 136, 138.

${ }^{42}$ Sucre a Santander, Quito, 21 de enero de 1823, Archivo Santander, vol. IX, 215.
} 
Santander pensó por primera vez, en junio de 1823, en emprender una campaña contra la isla de Puerto Rico; desde allí, las fuerzas monarquistas, al mando del general Morales, estaban dirigiendo varias operaciones contra las costas venezolanas. La estrategia de Santander fue inaugurada con su sello legalista. Como las leyes de la República solo tenían permitido destinar los fondos para la seguridad dentro de la frontera nacional, una eventual expedición fuera del territorio debía primero contar con la aprobación del Congreso. En una nota "muy reservada" enviada al presidente del Senado, le manifestó la necesidad de llevar a cabo una ofensiva contra Puerto Rico, pero que no solo debía desembocar en la reducción del poderío español y en la obtención de un armisticio, sino en su ocupación y anexión, recurriendo a "medios legales" que le permitieran "inclinar la voluntad de los habitantes de Puerto Rico" en ese sentido ${ }^{43}$. Seguramente, este paso no hubiera encontrado muchas dificultades prácticas debido a los lazos familiares entre los grandes hacendados venezolanos y puertorriqueños. En una nota de Fernando Peñalver a Santander se lee lo siguiente:

"Si la España sucumbe al Gobierno despótico que quiere restablecer Luis XVIII, hay mucha probabilidad de que Puerto Rico se úna a Colombia y la Habana a Méjico. Los jefes que mandan en Puerto Rico en lo militar y político están casados con caraqueñas y por sus mujeres tienen haciendas en Venezuela."44

Según Santander, si la isla de Puerto Rico quedaba reducida a la nada, "sería de grande peligro para la República, porque aislada y sin relaciones, podría ser presa, o del poder de Haití o de cualquiera otra nación extranjera. Una isla situada al frente de Colombia, cuyo canal es el preciso de comunicación con todas las Antillas, amenazaría continuamente nuestra seguridad y nuestro comercio desde el día en que ella fuese propiedad de una nación europea". Además, esta empresa debía ponerse en marcha para "ocupar útilmente la escuadra y un número de tropas que, permaneciendo en la ociosidad o despedidas del servicio, pudieran fomentar la turbación e inquietud interior". Finalmente, su propósito debía ser útil para hostilizar "de todos modos al enemigo hasta forzarle a pedir la paz"45.

El Congreso accedió a la petición de Santander sin mayores problemas, advirtiendo únicamente que no se expresara la idea de "inclinar la voluntad de que Puerto Rico pertenezca desde ahora definitivamente a Colombia" ${ }^{46}$. En una sesión secreta, varios meses después de

43 “Francisco de Paula Santander al excelentísimo señor presidente de la cámara del senado (muy reservado)", Palacio del Gobierno en Bogotá, 10 de julio de 1823, en Archivo Santander, vol. X, 262.

${ }^{44}$ Peñalver a Santander, Valencia, 6 de agosto de 1823, Archivo Santander, vol. XI, 15.

45 "Francisco de Paula Santander al excelentísimo señor presidente de la cámara del senado (muy reservado)", Palacio del Gobierno en Bogotá, 10 de julio de 1823, en Archivo Santander, vol. X, 261-262. Esta idea aparece de nuevo en otra nota de Santander a Bolívar de 2 de marzo de 1827, donde dice: "Magnifico, excelente y oportuno es el proyecto de expedicionar sobre Puerto Rico. Bien se conoce, que Ud. ha recordado la conducta del Senado Romano, que se sirvió siempre de guerras extrañas para distraer al pueblo y sufocar la discordia civil", en Archivo Santander, vol. XVI, 258. La nota de Santander respondía a un Oficio del Secretario de Bolívar al Secretario de Guerra fechada el 27 de enero de 1827, donde dice que la expedición no solo alejará "de todo el hemisferio aun las últimas reliquias del poder español, sino que pondremos en acción nuestras tropas, conservaremos su disciplina y daremos mayor firmeza a nuestra existencia y gloria nacional", en Memorias de O'Leary, XXV, 50.

${ }^{46}$ Esa nota fue firmada por los presidentes y secretario del Senado, Estanislao Vergara, y Francisco Soto, respectivamente, tal y como aparece al pie del oficio enviado por Santander, impreso en Santander y el Congreso de 1823. Actas y Correspondencia, Bogotá, Fundación para la Conmemoración del Bicentenario del Natalicio y el Sesquicentenario de la Muerte del General Francisco de Paula Santander. Biblioteca de la Presidencia de la República, 1989 (versión digital recuperada de: 
que el Congreso volviera de los largos recesos que solía tomarse, aprobó una ley el 24 de marzo de 1824 que le permitía al gobierno colombiano llevar a cabo una expedición sobre Puerto Rico y anexar la isla solo si los puertorriqueños decidían voluntariamente dar ese paso $^{47}$.

En cualquier caso, pocas semanas después de haber pasado su proyecto a la aprobación del Senado, en julio de 1823, las fuerzas republicanas derrotaron en Maracaibo al general Morales; Santander, por ello, no volvió a pensar en expediciones mientras no hubiera en el horizonte una amenaza de invasión a gran escala y mientras Bolívar estuviera consumiendo todos los recursos en Perú ${ }^{48}$. Sin embargo, Santander reservó para el futuro esa carta legal, aunque introduciendo diversos matices y sin salirse del guion bolivariano. Santander era un hombre de Estado cuyo carácter autónomo e ingenio administrativo le permitían imponer su sello a las decisiones políticas más relevantes; y con su característica y muy agria sensibilidad realista, la política antillana de Colombia adquirió una tonalidad distintiva: la disuasión era el marco general que debía guiar la estrategia diplomática, pero llegaría un punto en que el gobierno colombiano debía tomarse en serio esa empresa -esto es, darle a las fuerzas colombianas un nivel de credibilidad disuasorio respetable y, eventualmente, si se daban diversas circunstancias, ponerla en marcha.

Las razones que esgrimía Santander para anexar Puerto Rico eran muy evidentes. Pero ¿por qué la anexión de Puerto Rico en lugar de Cuba o de ambas? Para Santander, como se vio, la posesión de Puerto Rico estaba relacionada con consideraciones de orden estratégico e interno. En cuanto a Cuba, debía sopesar las consecuencias de una medida tan temeraria como audaz. Cuba era una fortaleza realista muy bien resguardada, ubicada a una mayor distancia de la costa firme colombiana, lo que hacía difícil plantar una batalla frontal sin sufrir serias derrotas ${ }^{49}$. Puerto Rico, en cambio, de menor extensión y no tan resguardada, era una presa fácil para las fuerzas colombianas, útil como una base estratégica para comandar su seguridad en el Caribe y plataforma de desplazamiento de las tropas ante un eventual bloqueo a La Habana ${ }^{50}$.

Si Santander tenía algún entusiasmo por la empresa antillana, un entusiasmo más bien inconexo y condicionado por múltiples variables, otros miembros de la aristocracia militar colombiana, en cambio, aupados por la necesidad de librarse de una vez por todas de la amenaza realista, promovieron fervorosamente la expedición "libertadora". Entre estos, sobresalían los oficiales José Antonio Páez y Antonio José de Sucre. Después de un encuentro que sostuvo en Puerto Cabello con los rebeldes cubanos, con su particular e inextinguible espíritu guerrerista, Páez se dirigió a Bolívar con la intención de aguijonear la expedición:

http://www.bdigital.unal.edu.co/5628/106/Santander_y_el_Congreso_de_1823_Actas_y_Correspondencia.ht $\mathrm{m \# s} 3 \mathrm{ca})$.

${ }^{47}$ Esa ley no llegó a publicarse. Solo se tiene noticia de ella por una comunicación del Secretario de Relaciones Exteriores, José Revenga, a los comisionados colombianos en el Congreso de Panamá, Pedro Gual, y Pedro Briceño Méndez (fechada el 14 de octubre de 1825, en Memorias del General O'Leary, XXIV, 287). También se tiene conocimiento de esta ley en una nota de Santander a Bolívar, Bogotá, 6 de junio de 1825, en Archivo Santander, vol. XIII, 23.

${ }^{48}$ Santander a Páez, Bogotá, 22 de febrero de 1824, Archivo Santander, vol. XI, 315-316.

${ }^{49}$ Santander a Bolívar, Bogotá, 6 de junio de 1825, en Archivo Santander, vol. XIII, 23-24.

${ }^{50}$ Esta concepción estratégica fue ampliada por Santander en una nota dirigida a Bolívar el 6 de junio de 1825 , en Archivo Santander, vol. XIII, 23. Bolívar estaba de acuerdo con ese planteamiento, tal y como lo dejaría traslucir unos años después, en enero de 1827. Ver más adelante.

110 Historia y Espacio • Vol.16. No. $55 \cdot$ julio-diciembre • pp. 96- $129 \bullet$ Universidad del Valle • E-ISSN 2357-6448 
"cuente conmigo y cuente con tres ó cuatro mil hombres de Venezuela, los más guapos, y que un mes después de recibidas las órdenes aquí, estaremos en la Habana" 51.

Sucre, por otra parte, comenzó a impulsar la idea de una expedición a inicios de $1823^{52}$. La aplastante victoria conseguida en la batalla de Ayacucho, que sonrió triunfalmente a las huestes republicanas a fines de 1824, abrió nuevas perspectivas. Y Sucre, como artífice de esa victoria, emprendió una nueva e incisiva campaña para comandar una expedición contra Cuba. Buscando alguna ocupación para sus 8.000 tropas veteranas, y con toda seguridad impulsado por su sensibilidad republicana y revolucionaria, envió una carta al gobierno colombiano ofreciendo sus servicios: "No sé si estaría en los intereses de Colombia alguna empresa sobre la Habana; pero me atrevo a indicarla, si es que se puede disponer de alguna marina con que protegerla ${ }^{53}$.

Ese espíritu aventurero también se puede apreciar en los pequeños círculos revolucionarios provenientes de Cuba y Puerto Rico. En abril de 1825 -como se sabe por las memorias de uno de los rebeldes cubanos-, Bolívar recibió en Lima a dos de ellos, José Rafael de las Heras y José Agustín Arango, quienes quedaron con la impresión de que el Libertador, tarde o temprano, iba a poner en marcha la expedición ${ }^{54}$. Unos meses antes, asediado por la arremetida realista en Perú, y desesperado por los persistentes ruegos del general puertorriqueño Antonio Valero, le envió una nota a Santander donde le decía: "Vea Vd. si se puede hacer algo contra la Habana"55. Efectivamente, el Libertador, entre 1825 y 1826 , respondía favorablemente y con algún entusiasmo a las peticiones hechas por los rebeldes cubanos y puertorriqueños, quienes gestionaron intensamente su apoyo para una futura expedición libertadora a gran escala. La antesala del Congreso de Panamá es un buen ejemplo de este escenario de promesas vagas: la Anfictionía estuvo adornada con la presencia de varios cubanos rebeldes -como José Agustín Arango, José Aniceto Iznaga y Fructuoso Gil del Castillo-, quienes llegaron a Panamá con la anuencia de Bolívar para darle mayor realce a la causa independentista ${ }^{56}$.

El propio Bolívar, de hecho, se figuró de vez en cuando alguna fantasía expedicionaria. Quizás la primera vez que reflejó este entusiasmo fue en 1815, en la llamada Carta de Jamaica. Posteriormente, en agosto de 1820, en una nota que le envió al general Santander, le decía: “¡Dios nos asista!, adiós del Perú y México; adiós de La Habana y Puerto Rico. Yo no le pido a Dios más que una victoria, porque las demás yo las tengo seguras" 57 . Pero, a pesar de todas esas promesas y fantasías exteriorizadas con alguna frecuencia, Bolívar seguía decantado por la salida diplomática por todas las razones expuestas en una sección anterior, aunque también con la esperanza de llevar un poco de reposo a su alma y al fisco colombiano:

\footnotetext{
${ }^{51}$ Páez a Bolívar, Puerto Cabello, 19 de agosto de 1824, Memorias de O’Leary, vol. II, 56.

${ }^{52}$ Sucre a Santander, Quito, 21 de enero de 1823, Archivo Santander, vol. IX, 215.

${ }^{53}$ Sucre al señor Secretario de estado del Despacho de la Guerra, La Paz, 8 de marzo de 1825; ver también Sucre a Santander, Oruro, 18 de marzo de 1825, y desde Potosí, 23 de abril, en Archivo Sucre, t. V, Caracas, Fundación Vicente Lecuna, Banco de Venezuela, 1978, 286-287, 321-322, 488.

${ }^{54}$ José Aniceto Iznaga, "Peregrinación patriótica a Colombia", 146.

${ }^{55}$ Bolívar a Santander, Pativilca, 25 de febrero de 1824, en Archivo Santander, vol. XI, 317. Leví Marrero, en su libro Cuba: Economía y Sociedad (p. 106), sostiene que esta petición de Bolívar fue por instancia de Valero. 56 Julián Vivanco, José Antonio Miralla. Precursor de la Independencia de Cuba.

${ }^{57}$ Bolívar a Santander, San Cristóbal, 8 de agosto de 1820, en Obras Completas, t. I (versión digital recuperada de: http://www.archivodellibertador.gob.ve/escritos/buscador/spip.php?article6830).
} 
"Me parecía bien que el gobierno de Colombia, por los medios que juzgase a propósito, intimase a la España que si en tanto tiempo no reconocía la independencia de Colombia y hacía la paz, estas mismas tropas irían inmediatamente a La Habana y Puerto Rico. Más cuenta nos tiene la paz que libertar esas dos islas...La Habana independiente nos daría mucho que hacer, la amenaza nos valdrá más que la insurrección...Este negocio bien conducido puede producir un grande efecto. Si los españoles se obstinaren, Sucre puede ir a una parte, y Páez a otra, porque ambos están animados del mismo deseo. Yo no sé como está eso de expedición española sobre la Costa Firme; si viniere, o fuere necesario, yo iría inmediatamente." 58

Pocos meses después, para no dejar lugar a dudas, le indicó a Santander: "Con respecto a la Habana, nos conviene decir a España, que si no hace la paz, pronto estará privada de sus dos grandes islas. El general Sucre tiene muchas ganas de que se verifique la expedición, pero yo no he podido verlo aún para explicarle mis ideas" 59 . Al descubrir las verdaderas intenciones de Bolívar, Sucre le manifestó su desilusión: "Mucho celebro que México se empeñe en la expedición a la Habana; pero yo he pensado que $\mathrm{Vd}$. ha desistido de ello, puesto que solo trata de mandar nuestras tropas para Venezuela ${ }^{60}$.

Santander siguió al pie de la letra las sugestiones de Bolívar, pero, al mismo tiempo, como encargado del poder ejecutivo, debía buscar una salida que le diera credibilidad y eficacia a la estrategia disuasoria. No había terminado de disiparse el humo de la derrota de Ayacucho cuando comenzaron a surgir nuevos y muy fuertes rumores de una expedición española que se estaba formando en los puertos de Cádiz, las Canarias, Galicia y la Coruña, que debía zarpar hacia Cuba; para Santander, al igual que Bolívar, el gobierno español no tenía la capacidad real para emprender una operación de reconquista, pero sus movimientos persisten para "hacer ostentación de su poder contra sus colonias" y "de incomodarnos y mantenernos en estado de guerra"61.

Para terminar de prender las alarmas, una escuadra francesa llegaría a Cuba conformada por 5.000 hombres, y de España otras dos fragatas y dos regimientos con unas 7.000 tropas, que se sumaron a los 11 buques de guerra y 3.500 soldados que estaban apostados en $\mathrm{Cuba}^{62}$. Incluso si las tropas francesas solo iban a "guarnecer" la isla, esa sola situación dejaba las manos libres a las fuerzas españolas para llevar a cabo una expedición contra las costas mexicanas y colombianas ${ }^{63}$. Las autoridades locales de Cartagena y Panamá estaban de hecho en alerta. Para aplacar los temores, Bolívar ordena el envío de 1.400 hombres al Istmo y otros 3.000 a las costas colombianas, manifestando la disposición de enviar otras 20.000 tropas veteranas en caso de que se verificara la expedición realista ${ }^{64}$.

\footnotetext{
${ }^{58}$ Bolívar a Santander, Lima, 20 de diciembre de 1824, Obras Completas, II (versión digital recuperada de: http://www.archivodellibertador.gob.ve/escritos/inicio.php).

${ }^{59}$ Bolívar a Santander, Arequipa, 20 de mayo de 1825, en Archivo Santander, vol. XII, 371.

${ }^{60}$ Sucre a Bolívar, La Paz, 28 de julio de 1825, Memorias de O’Leary, I, 283.

${ }^{61}$ Santander a Bolívar, Bogotá, 21 de junio de 1825, en Archivo Santander, vol. XIII, 51.

62 Santander a Bolívar, Bogotá, 21 de agosto de 1825, en Archivo Santander, vol. XIII, 123; y Bolívar a Santander, Potosí, 13 de octubre de 1825, 223-224.

${ }^{63}$ Santander a Mariano Montilla, Bogotá, 19 de agosto de 1825; y Bolívar a Santander, Potosí, 13 de octubre de 1825, Archivo Santander, vol. XIII, 118, 223-224.

${ }^{64}$ Bolívar a Santander, Potosí, 27 de octubre de 1825, Archivo Santander, vol. XIII, 253-254.
} 
Santander también ordenó la construcción de una armada más poderosa. A los 5 buques de guerra que ya tenía Colombia, gestionó la compra en los astilleros de Suecia de una escuadra conformada por un navío de 74 cañones, una fragata de 44, tres corbetas, dos bergantines y dos goletas ${ }^{65}$. Estos buques tardarían muchos meses en arribar a Colombia. Mientras tanto, Santander emprendió un frente diplomático más amplio dirigido a suplir la deficiencia de las capacidades marítimas colombianas.

\section{La diplomacia en los gabinetes y los recelos mexicanos}

Consciente de que Colombia no podía llevar a cabo la expedición sin ayuda de otro país, recibió de buen agrado la llegada de un representante mexicano a mediados de $1825^{66}$. El gobierno mexicano también tenía la intención de encontrar un aliado para hacer frente a los reductos realistas en Ulúa, pero al mismo tiempo frenar las -supuestas- ambiciones de Colombia en las Antillas ${ }^{67}$.

José Anastasio Torrens llegó a Bogotá a mediados de 1825. Rápidamente, el 19 de agosto, firmó con el gobierno colombiano un convenio consistente en llevar a cabo una expedición conjunta contra el puerto realista de San Juan de Ulúa ${ }^{68}$. Santander no solo accedió por los compromisos adquiridos en el tratado firmado en octubre de 1823 entre ambos gobiernos, sino -sobre todo- para hacer frente a la alarmante reagrupación de tropas realistas en el Caribe: la alianza con México le daba mayor capacidad disuasoria (u ofensiva).

\footnotetext{
${ }^{65}$ Santander a Bolívar, Bogotá, 21 de agosto de 1825, Archivo Santander, vol. XIII, 124.

${ }^{66} \mathrm{La}$ diplomacia mexicana se activó apenas tuvo conocimiento de los supuestos planes expedicionarios colombianos que debía ir a la vanguardia de los rebeldes colombo-cubanos agrupados en la logia de los Soles y Rayos de Bolívar. Esta noticia le llegó a las autoridades mexicanas por intermedio de su Encargado en Washington, José Anastasio Torrens, quien a su vez había sido informado por José María Salazar, el ministro colombiano y activo conspirador y patrocinador de la empresa cubana en los Estados Unidos. Ver Torrens al Secretario de Relaciones Exteriores, 13 de octubre de 1823, tomado de William Manning, Early diplomatic relations between the United States and Mexico (Baltimore: The Johns Hopkins Press, 1916), 99.

${ }^{67}$ El gobierno mexicano comunicó este temor a sus ministros en Londres y en Washington, encargándole a este último que se trasladara a Bogotá con el fin de impedir que las huestes bolivarianas llevasen a cabo solitariamente esa empresa. En una nota enviada por el Secretario de Relaciones Exteriores mexicano, Lucas Alamán, al encargado mexicano en Londres (Michelena), se lee lo siguiente: "Se cree que el Libertador de Colombia concluida la campaña del Perú, piensa dedicar toda su atención y todas las fuerzas de aquella República a apoderarse de Cuba y Puerto Rico. En tales circunstancias, la política exige del Gobierno de México que se dedique a hacerse de dicha Isla, si fuere posible, o por lo menos hacer que quede independiente y no se engrandezca con tan rica posesión ninguno de sus vecinos, y con ese fin se despacha con toda brevedad, de Ministro a aquella República al General Bustamante, con el objeto de operar de concierto sobre Cuba con las fuerzas unidas de Colombia y México, con el fin de hacerla independiente bajo la protección de ambas Repúblicas...", impreso en Lucas Alamán, El reconocimiento de nuestra independencia por España y la unión de los países hispano-americanos. Con una introducción por Antonio de la Peña y Reyes (México, Publicaciones de la Secretaria de relaciones exteriores, 1930), XII.

${ }^{68}$ El gobierno mexicano llevaba pidiendo a Colombia apoyo militar para esa expedición desde fines de 1823. Miguel Santamaría, el ministro colombiano en México, le informaba al Secretario de Relaciones Exteriores el 12 de octubre de 1823 lo siguiente: "El Gobierno de México me ha pedido suplique al de Colombia su auxilio y cooperación con la marina de que pueda disponer después de la gloriosa victoria de Maracaibo, como en ningún tiempo ni en más oportunas circunstancias pudiera recibirlo, temiéndose fundadamente que el general Morales, con las tropas que evacuaron nuestro territorio, agregadas a las aprestadas por el Gobernador y comercio de La Habana, puedan intentar algo sobre el país, contando con la fortaleza de Ulúa", citado en Ornán Roldán Oquendo, Las relaciones entre México y Colombia 1810-1862 (Tlatelolco, Secretaría de Relaciones Exteriores, 1974), 70. El texto del tratado se puede consultar en: http://www.bdigital.unal.edu.co/4773/1044/Relaciones_Diplomaticas_de_Colombia_y_La_Nueva_Granada.h $\underline{\mathrm{tml}}$.
} 
Santander tenía de hecho otros planes en mente. Su estrategia consistía en utilizar la alianza para "encerrar a los españoles en la isla [de Cuba] para que no se metan a hostilizar nuestras costas", no como una "expedición formal, porque no podemos hacerla por sí solos, estando muy bien guarnecida la isla". Más adelante, en esa misma nota dirigida a Bolívar, sentenció: "tengo entre manos y muy reservado el proyecto de bloquear a La Habana con una fuerte escuadra", bloqueo que "si no rinde la cuenta", lo hará pensar "formalmente en Puerto Rico..., autorizado por el Congreso para todo, que ha sido buena fortuna"69.

Una nota enviada por Torrens a su gobierno el 28 de junio de 1825, hace más explícito el plan "entre manos y muy reservado" de Santander:

"El plan es que los gobiernos de México y Colombia declaren en estado de bloqueo no sólo a Ulúa sino también a La Habana y Cuba, que la marina cruce delante de estos dos puertos de la isla y desembarque mil colombianos que fortifiquen en un punto; de el cual no hagan incursión alguna antes bien proclamen que no ban á forzar á los habitantes a tomar un partido contra su inclinación sino a auxiliarlos si quieren hacer su independencia: y si no limitarse a quitar los recursos a los españoles atacando su Comercio. Que reunido el Congreso de Panamá se debe proponer que las nuevas repúblicas levanten una marina para llevar la guerra á España cruzando el Mediterráneo y haciendo desembarcos; añadió que sin este plan no es practicable el bloqueo de Ulúa, no habiendo en nuestras costas puertos donde se reparen los buques que sufran de un combate: que en el caso del plan irán al puerto guarnecido por los colombianos en Cuba." 70

Aunque Santander estaba pensando en una operación limitada de "bloqueo" sobre los puertos de Santiago de Cuba y La Habana, Torrens creía que Colombia sí tenía ambiciones sobre la isla. Para el ministro mexicano, el convenio simplemente le iba a dar una ventaja a Colombia: "debo inferir que se trata de mandar buques como auxiliares, pero que realmente va ir a promover sus intereses impidiendo que México se adelante. Me confirma la disculpa de que Colombia no tiene pretensiones a Cuba..."71.

Santander, en realidad, no tenía "pretensiones" sobre Cuba y, de hecho, las que tenía sobre Puerto Rico se habían desinflado y quedaron condicionadas al éxito del bloqueo propinado a Cuba. ¿Estaban dispuestos a permitir una eventual anexión de Cuba por parte de México (o que esa isla pasara a ser parte de su zona de influencia directa)? Los diplomáticos colombianos en Estados Unidos o Panamá no acogían esa idea con entusiasmo. La toma de Ulúa en noviembre de 1825 les hacía temer que México emprendiera una expedición sobre Cuba de manera solitaria que la llevara de ese modo a adquirir una mayor preponderancia en América $^{72}$; por ello, era preferible que Cuba quedara separada de México ${ }^{73}$. En una nota enviada por la Secretaría de Relaciones Exteriores a los delegados colombianos en el Congreso de Panamá, Santander se decantó por una salida intermedia y estableció cuál debía

\footnotetext{
${ }^{69}$ Santander a Bolívar, Bogotá, 6 de junio de 1825, en Archivo Santander, vol. XIII, pp. 23-24; y Santander a Bolívar, Bogotá, 21 de agosto de 1825, Archivo Santander, vol. XIII, 124.

${ }^{70}$ Esta nota es tomada de Vivanco, José Antonio Miralla, tomo III, 175.

71 Torrens al Secretario de Relaciones Exteriores de México, 28 de junio de 1825, tomado de Luis Chávez Orozco (comp.), Un esfuerzo de México por la independencia de Cuba, (México: Publicaciones de la Secretaria de relaciones exteriores, 1930), XXXI.

72 Briceño Méndez a Santander, Panamá, 10 de enero de 1826, en Archivo Santander, vol. XIV, 22.

${ }^{73}$ Palacios a Santander, Filadelfia, 10 de noviembre de 1825, en Archivo Santander, vol. XIII, 282.
} 
ser la suerte de las islas antillanas en caso de que el bloqueo u ocupación colombo-mexicana rindiera algún fruto:

[Ustedes] se esforzarán á que los demás Estados confederados, contentándose con la gratitud y perfecta amistad que será consecuente al beneficio, se adhirieran a las disposiciones de aquella ley [de marzo de 1824 que amparaba una eventual anexión de Puerto Rico]; y ya que sea forzoso establecer al principio gobiernos provisorios, se deje á los habitantes de las islas ó provincias que sean libertadas, el tiempo y sosiego necesarios para determinar de su propia suerte ${ }^{74}$.

En otras palabras, la idea de una anexión de Cuba no estaba entre sus planes -y tampoco iba a permitir que México diera ese paso, excepto que los cubanos lo hicieran soberanamente; en cuanto a Puerto Rico, una eventual anexión solo iba a ser momentánea -como una base estratégica desde la cual seguir hostilizando a Cuba-, dejando a los criollos puertorriqueños que decidieran su suerte autónomamente.

Ahora bien, antes de pensar siquiera en la expedición, Santander tenía que sopesar primero algunas condiciones geopolíticas y militares. El proyecto de bloqueo no solo tenía que esperar el arribo de la escuadra mandada a construir en Suecia (y otra parte en Estados Unidos), sino que requería calibrar escrupulosamente las condiciones militares de Cuba que, como se dijo más arriba, estaba guarnecida por tropas francesas. En una nota enviada a Bolívar, Santander le explicó que había designado al general Clemente para que preparara una eventual expedición que debía zarpar desde Cartagena (en el marco del convenio con México), pero advirtiendo: “Clemente lleva instrucciones de jamás comprometerse contra las naciones neutrales, ni de intentar nada firme contra la Habana, y menos ahora que está guarnecida por tropas francesas" 75 .

Esta nota da la impresión de que Santander estaba pensando en un bluff -un engaño al ministro mexicano, recurriendo a la alianza formada con este para aumentar el nivel de la amenaza. Aunque es totalmente legítimo pensar en esa posibilidad, también es cierto que Santander pensó en una expedición como un último, muy remoto y limitado recurso dirigido simplemente a hostilizar las fuerzas españolas en el mar; y esta última opción, en cualquier caso, estaba subordinada a la salida diplomática. Incluso al conocer que las tropas francesas se marcharon de Cuba, removiendo "los temores que... alarmaron a Venezuela, al Istmo y a Cartagena"76, emprendió una nueva campaña diplomática en Europa. Inicialmente, ordenó a su Secretario de Relaciones Exteriores, Pedro Gual, que dirigiera una nota al encargado en París para que este consulte con el ministro Villele qué partido tomaría Francia en la defensa

\footnotetext{
${ }^{74}$ José Revenga a los Honorables señores Pedro Gual y Pedro Briceño Méndez, Bogotá, 14 de octubre de 1825 , en Memorias de O'Leary, vol. XXIV, 287.

${ }^{75}$ Santander a Bolívar, Bogotá, 21 de agosto de 1825, Archivo Santander, vol. XIII, 124.

76 Santander a Bolívar, Bogotá, 21 de septiembre de 1825; y Santander a Mariano Montilla, Bogotá, 19 de septiembre de 1825, Archivo Santander, vol. XIII, 172, 177. Santander, de hecho, creía tener el camino más despejado desde que asumió que Francia no tenía ni la capacidad ni el interés de apoyar a la corona española en sus planes de reconquista, en "Consejo ordinario de Gobierno del lunes 13 de mayo de 1824", en Fundación para la Conmemoración del Bicentenario del Natalicio y el Sesquicentenario de la Muerte del General Francisco de Paula Santander. Biblioteca de la Presidencia de la República. Administración Virgilio Barco. Bogotá, 1988 (versión digital recuperada de: http://www.bdigital.unal.edu.co/4923/31/Acuerdos_del_Consejo_de_Gobierno.html). En una carta de Santander a Mariano Montilla (Bogotá, 19 de agosto de 1825, Archivo Santander, vol. XIII, 118), se lee: "Todavía tengo por qué confiar en que los franceses no nos hostilizarán". Ver también Santander a Bolívar, Bogotá, 21 de junio y 20 de octubre de 1825, Archivo Santander, XIII, 51, 236.
} 
de las islas, "en virtud del permiso que le concede el derecho de la guerra" a la Gran Colombia en caso de llevar a cabo la expedición ${ }^{77}$. Santander quería evitar nuevos enemigos, más si eran "naciones neutrales tan fuertes"78. Lo que esperaba de esa gestión diplomática, por tanto, cuya instrucción llevaba inserta una amenaza de invasión de las islas, era que el gabinete francés comunicara la oferta a Madrid e influyera sobre la corona española para que esta se aviniera a un armisticio. Como le dijo a Bolívar: "Recuerdo que U. me dijo que hiciéramos una amenaza semejante al gobierno español, a ver si de miedo a perderlo todo, nos dejaba en paz por algún tiempo"79. Santander también ordenó a su agente en Londres que emprendiera una gestión similar, induciendo a la corona inglesa para que esta "proponga a la Francia que sea la mediadora con la España para hacer la paz"80.

En resumen, entre fines de 1825 e inicio de 1826, Santander ya había definido los contornos de la estrategia antillana: poco le importaba si Cuba quedaba en manos de los independentistas cubanos o de la corona española, desde que esta última quedara reducida "a una situación muy triste y embarazosa" que la obligara a firmar un armisticio ${ }^{81}$. Y esa estrategia disuasoria, combinada con el tímido nivel de entusiasmo expedicionario que reflejaba, tenía que ser avalada por Bolívar, quien por cierto la aceptó porque reafirmaba su vieja postura: "El bloqueo de Cuba me parece magnífico; si fuere preciso iremos allá; mas prefiero la paz por las razones de marras" $" 82$.

Mientras esperaba que surtiera efecto la amenaza, Santander recibió una noticia muy desalentadora: a los pocos meses de firmar el convenio con México, este gobierno envió una nota a su representante en Bogotá para que impidiera la salida de la Armada colombiana hacia el puerto veracruzano; las fuerzas mexicanas fueron capaces por sí solas de remover el último reducto español de costa firme, por lo que el convenio ya no quedaba con vigencia. Para Santander, este resultado, aunque favorable a la causa americana, se presentó como un movimiento adverso que debía ser revertido. ¿Cómo generar una amenaza creíble si ya no contaba con su aliado?

En enero de 1826, frustrado por el fracaso de la gestión diplomática y la "obstinación” de Fernando VII para otorgar el reconocimiento, agobiado además por la crisis fiscal y el ingente gasto militar que le producía el inextinguible estado de guerra con España, pensó en proponer una tregua de diez años ${ }^{83}$. Este nuevo plan tenía dos componentes: por un lado,

\footnotetext{
${ }^{77}$ Santander a Bolívar, Bogotá, 21 de septiembre de 1825, Archivo Santander, vol. XIII, 177.

78 Santander a Bolívar, Bogotá, 21 de septiembre de 1825, Archivo Santander, vol. XIII, 177.

${ }^{79}$ Santander a Bolívar, Bogotá, 21 de septiembre de 1825, Archivo Santander, vol. XIII, 177.

${ }^{80}$ Santander a Bolívar, Bogotá, 21 de julio de 1825, en Archivo Santander, vol. XIII, 81; y Hansard's Parliamentary Debates, XXIV, 1019-1023.

${ }^{81}$ Santander a Bolívar, Bogotá, 21 de enero de 1826, Archivo Santander, vol. XIV, 33.

${ }^{82}$ Bolívar a Santander, Potosí, 21 de octubre de 1825, Archivo Santander, vol. XIII, 245 (la cursiva es nuestra). Según Páez, Bolívar estaba pensando en ese mismo instante en planear una expedición para el futuro cercano. En sus Memorias publicó una carta en la que Bolívar le dice: "cada día estoy más y más determinado a ejecutar esta operación, de que resultará un inmenso bien a Colombia” (Bolívar a Páez, Potosí, 16 de octubre de 1825, impreso en Memorias, 454-455). Sin embargo, Bolívar se refería al envío de los batallones que cumplieron sus servicios en Perú, y que debían volver a las costas colombianas a prestar sus servicios de defensa ante un ataque o invasión realista, en Bolívar a Santander, La Paz, 1 de septiembre de 1825, y desde Postosí, 27 de octubre de 1825, Archivo Santander, XIII, 139, 254. Es posible que Sucre también creyera que Bolívar estaba planeando una expedición, como se puede inferir en una carta que le envió al Libertador desde La Paz el 28 de julio de 1825, Memorias de O'Leary, I, 283.

${ }^{83}$ En ese momento, los gastos del Estado eran de 16 a 18 millones de pesos; las rentas, en cambio, tan solo llegaban a los 7 u 8 millones; el ejército contaba con un enorme contingente de 23.000 hombres, y la inversión en la marina de guerra se hacía cada vez mayor. Para recuperar la economía, era preciso por tanto disminuir el
} 
conseguir el armisticio con la garantía y la mediación de Inglaterra y Francia; por el otro, en caso de que España no transigiera, aprovechar el tiempo dedicado a esa negociación para aumentar las capacidades y emprender una expedición de bloqueo no solo de las Antillas, sino de los puertos ibéricos, para destruir la armada española de fond en comble ${ }^{84}$. Santander le manifestó a Bolívar, con una furia inusitada, que esta era una medida necesaria si se quería por lo menos tener un periodo de paz estable ${ }^{85}$.

En cualquiera de los dos escenarios, era vital la alianza con México. Con ese fin, Santander envió un delegado ante el gobierno mexicano, con el que rápidamente, en marzo de 1826, se firmó un nuevo acuerdo. Santander esperaba que la alianza diera a la escuadra colombo-mexicana una fuerza equiparable a las fuerzas españolas de mar: mientras que España contaba con 18 navíos de guerra que transportaban 447 cañones, Colombia tenía apostados en Cartagena 7 navíos de 239, y México 18 navíos de 172. Combinada, la fuerza colombo-mexicana llegaba a 25 navíos de guerra con 411 cañones ${ }^{86}$. Santander, como se ha dicho, prefería promover una salida diplomática -recurriendo a la amenaza de una expedición conjunta con México-, pero por primera vez estaba dispuesto a enfilar baterías sin más limitaciones que la formación de la anhelada armada mandada a construir en Suecia y Estados Unidos $^{87}$. También amplió el frente diplomático en los Estados Unidos: el encargado colombiano en Washington, José María Salazar, fue instruido para lograr que este país gestionara ante la corona española la firma de un armisticio (o un tratado de paz definitivo), exigiendo que la corona española no aumentara sus fuerzas en las islas, a cambio de la renuncia colombiana a promover la independencia de $\mathrm{Cuba}^{88}$.

Bolívar conoció este nuevo plan en abril de 1826, en medio de uno de los tantos rumores de una invasión española dirigida desde Cuba. En la respuesta que le transmitió a Santander, dijo: "Apruebo mucho y me parece perfectamente concebido el plan de la expedición marítima y del armisticio. Esto es lo que nos conviene decididamente. Entiendo que es mejor un armisticio que una paz con España"89. Como se puede notar, Bolívar volvió a mostrarse entusiasmado con la idea de una expedición, pero prefería aún la salida diplomática. Hasta ese momento, enfocó todas sus energías y los recursos colombianos en mejorar la defensa y seguir apostando a la disuasión. En agosto de 1826, no obstante, en el marco del Congreso de Panamá, él mismo sería el principal impulsor de una expedición antillana.

\section{La política antillana en el marco del Congreso de Panamá: Bolívar promueve personalmente la expedición}

La idea de incluir la suerte de las islas antillanas en el Congreso de Panamá fue impulsada por Santander desde febrero de 1825, y se convirtió en un aspecto central, aunque todavía

ejército y "desembarazarse de la marina", en Santander a Bolívar, Bogotá, 21 de enero de 1826, Archivo Santander, XIV, 32-33.

${ }^{84}$ Santander a Bolívar, Bogotá, 21 de enero de 1826, Archivo Santander, XIV, 33. La cursiva en el original.

${ }^{85}$ Santander a Bolívar, Bogotá, 21 de enero de 1826, Archivo Santander, XIV, 33.

${ }^{86}$ José Manuel Restrepo, Historia de la Revolución de la República de Colombia en la América Meridional (Bogotá: Imprenta Nacional, tomo VI, 1945), 373, 518-519; para el caso mexicano, ver Hernán Venegas Delgado, "Los planes colombo-mexicanos de expedición conjunta para la liberación de Cuba", 12.

${ }^{87}$ Santander a Bolívar, Bogotá, 21 de enero de 1826, vol. XIV, 32-33.

${ }^{88}$ Salazar a Clay, New York, 19 de marzo de 1826, en D.C.I., II, 1297.

${ }^{89}$ Bolívar a Santander, Magdalena (Lima), 7 de abril de 1826, en Archivo Santander, vol. XIV, 216. 
con un carácter provisorio, de su estrategia disuasoria ${ }^{90}$. Bolívar también impulsó esa estrategia a través de sus agentes en Perú ${ }^{91}$. Como ya se ha insistido, el gobierno colombiano buscaba generar un mecanismo disuasorio eficaz con la formación de un contingente hispanoamericano poderoso. Sin embargo, los plenipotenciarios colombianos solo lograron formar una liga militar reducida a los contingentes de Colombia, México y Guatemala, sin incluir siquiera una referencia explícita de una expedición contra Cuba. Bolívar envió una nota a los delegados colombianos insistiendo desesperadamente en la necesidad de incluir esa referencia: ¿cómo, sin la existencia de una referencia explícita a una expedición, podría surtir efecto la estrategia disuasoria? Bolívar envió una nota a sus representantes recomendando que incluyeran esa referencia, antecedida por una advertencia en la que se indicaba un periodo de cuatro meses otorgado a España para que se decidiera por la paz; ese contingente de tropas también debía "defender cualquiera parte de nuestras costas que sea atacada por los españoles o nuestros enemigos", y finalmente tendría que "expedicionar contra La Habana y Puerto Rico; marchar a España con mayores fuerzas, después de la toma de Puerto Rico y Cuba, si para entonces no quisieren la paz los españoles"92.

Esta propuesta llegaría tarde, cuando el Congreso Anfictiónico ya había sido clausurado. De ese modo, la endeble liga militar, que ni siquiera llegaría a cristalizar en ninguno de los países signatarios, no incluyó una referencia a la expedición ${ }^{93}$. La exclusión de esa referencia no era gratuita. Los plenipotenciarios colombianos, por una parte, querían enviar un mensaje de prudencia a Europa, un llamado a la paz entre las naciones del mundo "civilizado"; asimismo, estos no hicieron alusión a las islas antillanas gracias a las sugestiones del delegado inglés en el Congreso de Panamá, quien enfatizó en los intereses de Estados Unidos y la "mediación” que este país estaba emprendiendo ante el gabinete ruso y español ${ }^{94}$.

Este último aspecto - la oposición de Estados Unidos- será abordado en la siguiente sección. Antes de ello, vale la pena indagar por qué el Libertador promovió personalmente

90 Gaceta de Colombia, Bogotá, 27 de febrero de 1825, no. 176, 177. Para las instrucciones a los plenipotenciarios colombianos, ver José Revenga a los señores Pedro Gual y Pedro Briceño Méndez, Bogotá, 14 de octubre de 1825, Memorias de O'Leary, XXIV, 286-287. Esta estrategia también aparece revelada por el encargado mexicano en Bogotá, José Anastasio Torrens, en la citada nota reservada del 28 de junio de 1825, en Vivanco, José Antonio Miralla. Precursor de la Independencia de Cuba, tomo III, 175.

${ }^{91}$ Debe recordarse que Bolívar ejerció funciones dictatoriales en Perú hasta febrero de 1825; tras su renuncia, uno de sus agentes, el general Tomás Heres, casualmente llegó a ocupar por varias semanas el cargo de Secretario de Relaciones Exteriores. Heres emitió las instrucciones a los delegados peruanos en mayo de 1825. Ver la correspondencia enviada por éste a Bolívar, en Memorias de O’Leary, vol. V, Lima, 30 de abril y 25 de mayo de 1825, 95, 102. Para un balance, ver la obra citada de Roig de Leuchsenring, Bolívar, el Congreso Interamericano de Panamá, 28-31.

92 José Gabriel Pérez (Secretario de Bolívar) a los Señores Plenipotenciarios de Colombia en la Asamblea de Panamá, Lima, agosto de 1826, en Memorias de O'Leary, XXIV, 376. Una nota similar es escrita por el propio Bolívar a los plenipotenciarios, fechada el 11 de agosto de 1826, en Memorias del O'Leary, XXVIII, 561-562. No se puede decir con certeza qué significado le estaba dando Bolívar en ese momento al término "toma de Puerto Rico o Cuba", pero por notas posteriores, se puede decir que esa "toma" era momentánea y dirigida a independizar las islas para eliminar el último reducto español en América (ver la última sección).

${ }^{93}$ Para una referencia sobre las fuerzas o contingentes militares de la alianza forjada en Panamá, ver el texto en “Tratado de Unión, Liga y Confederación Perpetua de las Repúblicas de Colombia, Centroamérica, Perú y Estados Unidos Mexicanos. Panamá", 15 de Julio de 1826, impreso en Germán de la Reza, Documentos del Congreso Anfictiónico de Panamá, 207-217.

94 Pedro Briceño Méndez al señor Secretario de Estado del Departamento de Relaciones Exteriores de Colombia, Bogotá, 15 de agosto de 1826, en Memorias de O'Leary, XXVIII, 573-574. 
la puesta en marcha de una expedición. Su principal consideración era de orden interno, un factor que en todo caso estaba estrechamente conectado con los cambios desfavorables en la distribución del poder entre España y Colombia, así como en una transformación de las percepciones de las actitudes de las potencias europeas.

Cuba se había constituido en una base desde donde España podía fomentar las disensiones en Costa Firme a través de la introducción de realistas exiliados y de propaganda monarquista, así como de una eventual expedición militar cuando esas disensiones dieran paso a la debilidad y la anarquía ${ }^{95}$. Los realistas exiliados en la isla de Cuba, de hecho, instaban con alguna frecuencia a que se realizara una expedición contra México, Panamá o las costas venezolanas. Específicamente, Bolívar temía que la rebelión de Páez fuera aprovechada por las fuerzas leales a la monarquía española, que "tienen mucho partido en Venezuela y que con 3,000 hombres basta para tomar aquel país porque cuentan levantar $6 \mathrm{u}$ 8,000 godos...Yo no dudo que levantarán contra nosotros la gente del pueblo para destruirnos" 96 . En ese mismo marco, en junio de 1826, tuvo conocimiento de una posible expedición ordenada por el gobernador de Cuba contra el Istmo de Panamá: "Me parece que fuera muy conveniente y útil a nuestra tranquilidad que ustedes hicieran correr la voz de que yo voy al Istmo con 12,000 hombres a hacer una expedición contra la Habana. No es difícil conocer el objeto de esta política"97.

Hacia junio de 1826, como se ve, Bolívar aún seguía decantado por la estrategia disuasoria. Sin embargo, a esas alturas tampoco estaba dispuesto a tolerar por más tiempo la incertidumbre que le producía el estado de guerra con España, por lo que en algún punto debía pensar también en una campaña ofensiva. Diversos motivos lo llevaron a pensar en esta última posibilidad: los alarmantes movimientos que se fraguaban en Cuba, la proximidad de la reunión anfictiónica y la recuperación del fisco nacional a través de la disminución de las fuerzas militares colombianas. Dentro de su concepción estratégica, como se dijo más arriba, primero debía esperar si la amenaza de una expedición surtiría el efecto esperado en el plazo de cuatro meses; en caso contrario, estaba dispuesto a emprender una campaña militar ofensiva con sus socios continentales, un paso que de hecho no estaba dispuesto a dar sin contar con este bloque: la alianza forjada con México por el general Santander era el primer escalón, aunque esta debía salir reforzada con una nueva y más auspiciante alianza conformada por otros Estados de la región ${ }^{98}$. Bolívar se había tomado tan en serio esta empresa, que comenzó a dar rienda suelta a sus colaboradores más entusiastas de la expedición. Sucre, por ejemplo, fue "convidado" por el Libertador, a lo que aquel respondió efusivamente: “...me convida usted á la expedición a La Habana; no sólo la acepto por mil motivos de gratitud y de gloria, sino que la anhelo; creo que ella á un tiempo sirve á los intereses de Colombia y de la América"99.

Si Bolívar no estaba dispuesto a poner en marcha la expedición antillana sin el respaldo de algún aliado hispanoamericano, ¿estaba pensando en la aquiescencia de Gran Bretaña? Aunque es difícil establecerlo con total certeza, todo parece indicar que a mediados de 1826 no tuvo en cuenta del todo la actitud británica -o quizás pensó que esta era más

\footnotetext{
95 Bolívar a Briceño Méndez, Magdalena (Lima), 14 de junio de 1826, en Obras Completas (versión digital recuperada de: http://www.archivodellibertador.gob.ve/escritos/buscador/spip.php?article3275).

${ }^{96}$ Bolívar a Santander, Magdalena, 13 de junio de 1826, en Archivo Santander, vol. XV, 7.

${ }^{97}$ Bolívar a Santander, Magdalena, 13 de junio de 1826, Archivo Santander, vol. XV, 8.

${ }^{98}$ Bolívar a los Plenipotenciarios de Colombia, Lima, 11 de agosto de 1826, en Memorias del O'Leary, XXVIII, 561-565.

${ }^{99}$ Sucre a Bolívar, 13 de septiembre de 1826, Memorias de O’Leary, vol. I, 390-391.
} 
favorable. Bolívar llevaba insistiendo casi dos años en la necesidad de vincular a la corona británica en una alianza defensiva que tomara "en sus manos el fiel de esta balanza [la Anfictionía]" 100 . Sin embargo, en agosto de 1826, cuando convirtió la empresa antillana en una cuestión de vital importancia, aún no conocía la respuesta oficial de Inglaterra en torno a la propuesta presentada por el gobierno colombiano consistente en convertir a esa potencia en la "protectora" de la América hispana ${ }^{101}$. La alianza con Inglaterra le daba sin duda mayor credibilidad a la disuasión, pero con o sin una respuesta favorable de esa potencia, Bolívar tenía a esas alturas una impresión más positiva de la corona británica ${ }^{102}$.

Lo que sí es seguro es que el Libertador ya no temía a los “santos aliados” de España. Como le dijo a Santander, la Santa Alianza:

“...está fundada sobre un sistema artificial, y por lo tanto muy frágil...yo no temo nada en el día porque puedo disponer de la mayor parte de las fuerzas americanas, y porque no temo de la Europa grandes tentativas, que no se encuentren contrarrestadas por la Inglaterra."103

Ahora bien, como la amenaza de una expedición realista desde Cuba era cada vez más alarmante y, como las gestiones en Europa no daban ningún fruto, sentenció: "nada tenemos que esperar de la Europa y que cuanto hagamos debe salir de nuestro patriotismo y de nuestros sacrificios"104. La proyectada expedición antillana de agosto de 1826, por tanto, había sido básicamente condicionada por el temor a una expedición española y la amenaza existencial que esta representaba para la supervivencia del régimen republicano. Si esa empresa no prosperó, fue básicamente porque no tenía ninguna perspectiva real de éxito con la débil y poco temeraria fuerza militar que se forjó con los gobiernos de México y Guatemala; en ese entonces, Bolívar no estaba atado por el temor a la oposición británica o francesa, y en cualquier caso estaba dispuesto a vencer esa dificultad con su singular tenacidad.

La expedición proyectada entre agosto y septiembre de 1826, ¿fue paralizada por el temor a la oposición estadounidense? No existe certeza. En cambio, el plan expedicionario ideado por el Libertador en enero de 1827 refleja claros indicios de esta oposición.

\section{La reacción de Estados Unidos}

En la sección anterior se dijo que el encargado de Colombia en Estados Unidos, José María Salazar, fue instruido para solicitar la mediación de este gobierno. Salazar no tuvo que insistir

\footnotetext{
100 "Bolívar: Un pensamiento sobre el Congreso de Panamá, Lima, Febrero de 1826".

101 Bolívar solo vino a conocer la respuesta -negativa- varios meses después, en Santander a Bolívar, Bogotá, 23 de diciembre de 1826, en Archivo Santander, vol. XVI, 85. Ver la Segunda Parte.

102 Ver, en este último sentido, Bolívar a Santander, Potosí, 21 de octubre de 1825, Archivo Santander, vol. XIII, 243. Sobre el peso de Gran Bretaña en la futura Confederación hispanoamericana, ver "Bolívar: Un pensamiento sobre el Congreso de Panamá, Lima, Febrero de 1826".

${ }^{103}$ Bolívar a Santander, Potosí, 13 de octubre de 1825, Archivo Santander, vol. XIII, 224.

104 Bolívar al Señor General Don Antonio Gutiérrez de La Fuente, Magdalena (Lima), 4 de mayo de 1826, Biblioteca Nacional de Lima (versión digital recuperada de: http://www.archivodellibertador.gob.ve/escritos/inicio.php
} 
mucho en ello, ya que las élites estadounidenses tenían su propia y muy interesada política antillana.

Esa política aparece resumida en una carta que le envió el Secretario de Estado Henry Clay al ministro estadounidense en México, Joel Poinsett, en la que se puede percibir el temor que produciría una operación combinada entre Colombia y México en las Antillas españolas. De acuerdo a Clay, esa operación alteraría el comercio y la seguridad de los Estados Unidos, asuntos "que se hallan demasiado íntimamente relacionados con la fortuna y la suerte de la isla de Cuba para que puedan mirar ningún cambio de su condición y de sus relaciones políticas sin profunda alarma y cuidado" 105 .

La política antillana del gobierno de Estados Unidos se formó desde mucho tiempo atrás. Cuba y Puerto Rico se habían constituido en dos activos estratégicos vitales para esa potencia desde que se independizó de Gran Bretaña ${ }^{106}$. Para el gobierno de los Estados Unidos -que representaba o intentaba equilibrar los intereses de los grandes comerciantes y hacendados esclavistas del sur-, la suerte de Cuba debía estar atada a una de dos posibilidades: continuar bajo el dominio español o eventualmente anexarse a la Unión americana. Por Cuba, de hecho, pasaban casi tres cuartas partes del comercio exterior estadounidense; una Cuba fuera de su control, por otra parte, era una "amenaza" de índole socio-demográfico si se alteraba su status esclavista. En este último sentido, las élites estadounidenses querían evitar que se removiera la cuestión racial, y Bolívar, en ese sentido, era visto como el comandante de un frente bélico conformado por tropas "mestizas" cuyas guerras de "conquista" proyectadas hacia Cuba y Puerto Rico amenazaban los intereses económicos de las élites del sur de Estados Unidos; para estas, la "conquista" de las islas podría propagar una guerra "racial" hacia el interior del continente, amenazando con ello el sistema esclavista como su fuente de riqueza y poder ${ }^{107}$.

Ahora bien, mientras más difícil se hacía para España sostener sus viejos dominios coloniales, más apremiante se hacía para Estados Unidos evitar que las islas cayeran bajo la dominación de Colombia o México, y antes que estos, de Gran Bretaña o Francia; en el primer caso, tanto México como Colombia eran dos Estados incapaces de sostener la independencia de esas islas, lo cual traería más inestabilidad a la región y al mismo tiempo podría perjudicar los beneficios comerciales adquiridos con España. En cuanto al segundo, durante varios años, entre 1817 y 1826, el gobierno de Estados Unidos llegó a creer que Cuba estaba bajo la mira de los designios imperiales británicos y franceses. La corona británica también se sentía satisfecha si se preservaba el statu quo territorial a favor de España (o eventualmente como un Estado independiente dominado por las élites blancas), y con ello el status social en la región ${ }^{108}$. Gran Bretaña reconocía el derecho de Colombia, como beligerante, de atacar a España y tomar posesión de sus colonias, pero como dijo Canning: "esa guerra podría ser perjudicial para Inglaterra, causando una insurrección de los negros", que ascendían a unos 150.000 de un total de 500.000 habitantes en Cuba. La invasión de las fuerzas republicanas,

\footnotetext{
105 Clay a Poinsett, Washington, 26 de marzo de 1825, D.C.I., vol. I, 231-232.

${ }^{106}$ Como le dijo James Madison a William Pinkney (Washington, 30 de octubre de 1810): “La posición de Cuba le da a los Estados Unidos un interés tan profundo en el destino incluso de esa isla, que...estos no podrían ser un espectador indiferente si cae bajo cualquier gobierno europeo..., [ya que iba] en contra del comercio o la seguridad de los EE. UU." (versión digital recuperada de: https://founders.archives.gov/documents/Madison/03-02-02-0762).

${ }^{107}$ Los debates en el Congreso de Estados Unidos sobre este asunto están en Frederick Jackson Turner, Rise of the new West, 1819-1829 (New York and London: Harper \& brothers, 1906), 282-285.

${ }^{108}$ Hansard's Parliamentary Debates, vol. XXIV, 1019-1023.
} 
por tanto, era vista como una amenaza a los intereses de los plantadores ingleses del Caribe, ya que propagaría una guerra racial en sus posesiones antillanas y daría el pretexto para que otras potencias [esto es, Estados Unidos] interfirieran en los asuntos de Cuba "y ocupen la Isla a la fuerza", obligando a Inglaterra a intervenir para restablecer el equilibrio en el Caribe $^{109}$. A la larga, después de diversas gestiones y crisis diplomáticas desatadas en los gabinetes de Londres y París, estas tres potencias lograron una suerte de equilibrio tripartito consistente en preservar el status colonial de las islas ${ }^{110}$.

Por todos esos motivos, la expedición colombo-mexicana llegaría a sumar, en conjunto con la amenaza de las potencias europeas, una nueva causa de alarma para los intereses de los Estados Unidos. Y, si no era posible en ese momento tener el control total de las Antillas, la diplomacia estadounidense debía centrarse en evitar -de forma sutil preferentemente y recurriendo a la coerción en última instancia- que esas islas se esfumaran de las manos de España. Estados Unidos no dejó de vigilar a Gran Bretaña y a Francia (y viceversa) ${ }^{111}$, pero a partir de marzo de 1825 , como se dijo, la política estadounidense viraría decisivamente hacia las repúblicas hispanoamericanas.

Con relación a Colombia, inicialmente, la suerte de las islas antillanas se dilucidó bajo un ambiente muy cordial. El 5 de mayo de 1825, José María Salazar dirigió una nota al Secretario de Estado, Henry Clay, solicitando los buenos oficios de Estados Unidos para que esta potencia gestionara el reconocimiento de España ${ }^{112}$. Poco tiempo después, Clay se dirigió a Salazar con una noticia inmejorable: le dijo que Estados Unidos había instruido a sus Encargados en las cortes europeas para gestionar la finalización de la guerra entre España y sus antiguas colonias ${ }^{113}$.

El aspecto central del plan de Clay (aprobado por el presidente Adams) consistía en recurrir al influjo del zar Alejandro para que este convenciera al rey Fernando VII de la conveniencia de terminar la guerra y reconocer las repúblicas que recientemente habían conseguido su independencia; a cambio, Estados Unidos, en conjunto con las otras potencias, le garantizarían sus posesiones insulares ${ }^{114}$.

Santander y sus colaboradores acogieron "con entera satisfacción este paso de amistad sincera" 115 , y terminaron de acomodarlo como un aparente avance a su favor. Ahora

${ }^{109}$ Canning a Huratado, Londres, 24 de diciembre de 1825, en Hansard's Parliamentary Debates, vol. XXIV, 1021-1023.

${ }^{110}$ Para una detallada historia de las negociaciones, ver Bradford Perkins, Castlereagh and Adams: England and the United States, 1812-1823 (Berkeley: University of California Press, 1964), 316-320; y Harold William Temperley, The foreign policy of Canning, 1822-1827; England, the neo-Holy alliance and the New World (London: G. Bell and Sons, Ltd., 1925), 169. Ver también las memorias de John Quincy Adams, Memoirs of John Quincy Adams, comprising portions of his diary from 1795 to 1848 (Philadelphia:, J.B. Lippincott \& Co, 1874-77), vol. 6, p. 547, y vol. 7, p. 9. Para una visión de los intereses franceses en las Antillas, ver la obra citada de Hernán Venegas Delgado, La Gran Colombia, México y la independencia de las Antillas Hispanas (1820-1827), capítulo 4.

111 Temperley, The foreign policy of Canning, p. 170; y Perkins, Castlereagh and Adams, p. 338.

112 Salazar a Clay, Washington, 5 de mayo de 1825, D.C.I., II, p. 1283.

113 Clay a Middleton (agente en Moscú), Washington, 10 de mayo de 1825, en D.C.I., I, pp. 244-250; Clay a Everett (agente en Madrid), 27 de abril de 1825, Washington, D.C.I., I, p. 242. Para un balance del intercambio de impresiones entre el encargado colombiano y el Secretario de Estado, ver Salazar a Clay, Washington, 30 de diciembre de 1825, D.C.I, II, pp. 1288.

${ }^{114}$ Clay a Middleton, Washington, 10 de mayo de 1825, en D.C.I., I, 244-250.

115 Salazar a Clay, Washington, 30 de diciembre de 1825, D.C.I, II, 1288. Santander, en Bogotá, también manifestó su regocijo, en Anderson a Clay, Bogotá, 9 de marzo de 1826, y Revenga a Anderson, Bogotá, 17 de marzo de 1826, y Revenga a Anderson, Bogotá, 17 de marzo de 1826, D.C.I., II, 1293, 1296. La "mediación" 
bien, había un aspecto del plan de Clay que la diplomacia colombiana solo llegó a conocer en marzo de 1826: se trataba de la interposición de Estados Unidos, política que se define básicamente como la oposición de ese país a la expedición colombiana o mexicana usando como pretexto la mediación que estaba gestionando ante las cortes europeas ${ }^{116}$.

Mientras esperaba algún resultado favorable, y también para tener un gesto de cortesía diplomática con los Estados Unidos, el gobierno colombiano prometió detener la -supuestaexpedición que tenía planeada dirigir contra Cuba en conjunto con México. Sin embargo, lo hizo advirtiéndole a Anderson que la decisión final se adoptaría en la reunión continental que debía celebrarse en Panamá: los meses que preceden al Congreso eran suficientes para esperar una respuesta de España. Como dijo el Secretario de Relaciones Exteriores: el gobierno de Colombia "no acelerará, sin razones de peso, operación alguna de gran magnitud contra las Antillas españolas, hasta que sometida la proposición al juicio del Congreso Americano del Istmo se resolviera de concierto por los aliados"117.

Con ese paso, el gobierno colombiano quería mantener -o aparentar mantener- cierto margen de maniobrabilidad. Por supuesto, la mediación estadounidense no contradecía la política colombiana, pero sí le podía quitar credibilidad disuasoria a su proyectada expedición: ¿cómo disuadir a España si anunciaba su renuncia a la expedición? El general Santander resume esta dualidad en una nota que le envió a Bolívar: "yo haré contestar [a los Estados Unidos] en términos equívocos a fin de no desairar la interposición ni declarar que suspenderemos nuestros preparativos, lo cual daría mucho contento a los enemigos y los animaría a venir a hostilizar a nuestra costa"118. Santander también ordenó a Salazar reforzar la presión diplomática en Washington (así como a sus agentes en París y Londres), cuidando que el gobierno de Estados Unidos continuara con sus "buenos oficios" ante las potencias europeas -cuyo fin debía ser la firma de un armisticio-, pero siempre dejando abierta la posibilidad de una expedición ${ }^{119}$.

España, sin embargo, mantuvo inalterable su política. Y así como las gestiones en Moscú y Madrid no arrojaron ningún resultado, ante la corona británica se presentó un resultado igual de desalentador. Además, a mediados de 1826, en medio de las deliberaciones del Congreso de Panamá, los delegados colombianos comenzaron a descubrir la dura realidad: la interposición estadounidense no era muy neutral como se presumía -incluso cuando esta era vista como una política que favorecía sus intereses. Como se vio anteriormente, la oposición de Estados Unidos debía hacerse oficial en Panamá, pero los

estadounidense fue anunciada oficialmente al gobierno colombiano por el ministro Anderson a inicios de 1826, incluyendo la carta enviada por Clay a su Encargado en Rusia (de 10 de mayo de 1825), donde lo instruía para lograr la mediación del zar, en Anderson a Clay, Bogotá, 7 de febrero de 1826, en D.C.I., II, 1291-1292.

116 Ver la nota de Leandro Palacios a Santander (New York, 22 de marzo de 1826, Archivo Santander, vol. XIV, 166), donde le dice que en el Congreso de Panamá "la idea de Estados Unidos será influir por medio de sus Representantes para que no se emprendan operaciones contra la isla de Cuba...". Y la nota del delegado colombiano ante el Congreso Anfictiónico, Pedro Briceño Méndez, donde le dice a Santander que la oposición estadounidense a la expedición tiene la ventaja de dejar a Cuba en statu quo, sin que nadie adquiera preponderancia, ni Inglaterra, ni México, en Briceño Méndez a Santander, Panamá, 30 de marzo de 1826, en Archivo Santander, vol. XIV, 191.

${ }^{117}$ Revenga a Anderson, Bogotá, 17 de marzo de 1826, D.C.I., II, 1296; ver también Anderson a Clay, Bogotá, 7 de febrero de 1826, en D.C.I., II, 1291-1292.

118 Santander a Bolívar, Bogotá, 6 de marzo de 1826, en Archivo Santander, vol. XIV, 126.

${ }^{119}$ Salazar a Clay, New York, 19 de marzo de 1826, en D.C.I., II, 1297. Para las gestiones en las cortes europeas, ver las secciones anteriores. 
delegados estadounidenses no llegaron siquiera a establecerse en la Anfictionía. Sin embargo, el solo hecho de conocer la posición de ese país sería suficiente para que los plenipotenciarios colombianos no incluyeran una referencia a la expedición entre los objetivos que debía completar la alianza continental, ignorando incluso con ello las instrucciones de Bolívar ${ }^{120}$.

Durante las semanas críticas de agosto y septiembre de 1826, en las que tomó en sus propias manos la política antillana, Bolívar estaba dispuesto a ponerla en marcha incluso conociendo la interposición (es decir, la oposición) de Estados Unidos. Poco después, con el ánimo más sereno, reconociendo la derrota diplomática sufrida en Panamá y apremiado también por la necesidad de recuperar la sostenibilidad fiscal de Colombia, ordenó en noviembre de 1826 "desarmar” lo poco que se había construido de la Armada colombiana ${ }^{121}$. Por el momento, no se podía pensar más en planes expedicionarios.

A fines de enero de 1827, sin embargo, surgió una nueva oportunidad. Este plan fue resucitado por Bolívar cuando tuvo noticia de la crisis que estalló entre España e Inglaterra en torno a la lucha por el control de la política portuguesa; Bolívar llegó a creer que esa crisis se iba a transformar en una guerra, y que en tal caso debía emprender la formación de una alianza con Gran Bretaña con el fin de conformar un flanco anglo-colombiano en el Caribe español. Si estallaba la guerra, y se conformaba la alianza, Bolívar entonces aprovecharía la vulnerabilidad española para "emancipar" las islas de Cuba y Puerto Rico y, con ello, erradicar la presencia realista en América propinándole una derrota decisiva a España ${ }^{122}$. Para infortunio de Bolívar, la guerra entre España y Gran Bretaña no llegaría a estallar, y su plan se engavetaría de manera definitiva ${ }^{123}$.

Este último intento fue proyectado porque Bolívar esperaba formar una alianza con Gran Bretaña que le permitiera remover, precisamente, el obstáculo que presentaba la corona inglesa a esta empresa ${ }^{124}$, pero también los Estados Unidos. Tras un encuentro que sostuvo Bolívar en Caracas con los rebeldes cubanos en febrero de 1827, uno de ellos, José Aniceto Iznaga, dijo lo siguiente:

En ese mismo año de 1826 [1827, sic] dijo Bolívar con pesaroso acento á la comisión de cubanos que le visitó en Caracas las siguientes palabras: «No podemos chocar con el gobierno de los Estados Unidos, quien, unido al de Inglaterra, está empeñado en mantener la autoridad de España en las islas de Cuba y Puerto Rico, no obstante que esa determinación nos ha de mantener en constante alarma y nos causará gastos crecidos, á fin de repeler cualquiera tentativa desde esas islas por nuestro tenaz enemigo ${ }^{125}$.

\footnotetext{
${ }^{120}$ Ver la sección anterior.

121 "Consejo Extraordinario del sábado 18 de noviembre de 1826”, en Acuerdos del Consejo de Gobierno de la República de Colombia, 1821-1827 (versión digital recuperada de: http://www.bdigital.unal.edu.co/4923/31/Acuerdos_del_Consejo_de_Gobierno.html). Sobre la frustración de Bolívar en torno al Congreso de Panamá, ver Bolívar a Briceño Méndez, Guayaquil, 14 de Septiembre de 1826, en Obras Completas (versión digital recuperada de: http://www.archivodellibertador.gob.ve/escritos/inicio.php) 122 Oficio del Secretario de Bolívar al Secretario de Guerra, 27 de enero de 1827, en Memorias de O’Leary, XXV, 50; Bolívar a Pedro Briceño Méndez, Caracas, 25 de enero de 1827, y Bolívar a Mariano Montilla y José Padilla, Caracas, 27 de enero de 1827, Memorias de O’Leary, XXX, 324, 326-327.

${ }^{123}$ Bolívar a Urdaneta, Caracas, 5 de febrero de 1827; y Bolívar a Briceño Méndez, Caracas, 6 de febrero de 1827, Memorias de O’Leary, XXX, 332 y ss.

${ }^{124}$ Oficio del Secretario de Bolívar al Secretario de Guerra, 27 de enero de 1827, en Memorias de O’Leary, $\mathrm{XXV}, 50$

125 José Aniceto Iznaga: "Por qué Cuba y Puerto Rico no fueron libertadas por Bolívar", en Emilio Roig de Leuchsenring, Bolivar, el Congreso Interamericano de Panamá, 156.
} 
Vale la pena discutir algo más estas palabras de Bolívar. De acuerdo al historiador inglés Hugh Thomas, Bolívar usó como excusa de su inacción la oposición de Estados Unidos. Thomas sostiene que este país no tenía el poder suficiente para detener una expedición colombo-mexicana, y que si Bolívar hubiese tomado la iniciativa terminaría “desenmascarando" a Clay y al presidente Adams ${ }^{126}$. Aunque válida, esa interpretación tiene un problema: el plan de enero-febrero de 1827 sí refleja la intención de emprender una expedición para consolidar su obra independentista en el continente, y la oposición de Estados Unidos, así la inglesa, lo disuadieron definitivamente.

Después de frustrado este plan, no se volvió a pensar en Colombia en la expedición antillana, excepto como una idea, un discurso incendiario o una serie de declaraciones filantrópicas de los liberales decimonónicos ${ }^{127}$.

\section{Conclusión}

La política antillana de la Gran Colombia se delineó como una estrategia disuasoria. Esta caracterización, que ha sido desconocida por la Historia Diplomática colombiana, no solo permite captar de forma integral el verdadero sentido de la estrategia propiamente dicha, sino también enmarcarla en una estructura más amplia relacionada con la geopolítica internacional y la estructura interna colombiana. En este último sentido, tanto Bolívar como Santander, si bien se curtieron como figuras revolucionarias con un inagotable espíritu idealista y romántico, subordinaron todos estos idearios a los dictados de la Realpolitik: como hombres de Estado, también debían pensar en la preservación del régimen republicano, dando prioridad a este último objetivo.

La política antillana, en este sentido, se definió como una estrategia que andaba a mitad de camino entre la necesidad de persuadir a España para que esta potencia otorgara el reconocimiento y cesara su actitud hostil, y la incapacidad de las élites colombianas para emprender una campaña libertadora contra sus posesiones insulares en el Caribe. El punto intermedio de esa política consistía precisamente en no emprender una expedición militar, pero al mismo tiempo amenazando con llevarla a cabo. Esta política implicaba un gasto ingente en recursos y formación de alianzas, así como una valoración constante del entorno geopolítico internacional, esfuerzos todos que iban dirigidos a aumentar el nivel de credibilidad de la amenaza y, con ello, obtener el reconocimiento de España. Sin embargo, y esta es otra conclusión importante, la disuasión podía fallar, por lo que Bolívar (y Santander) tenían que pensar en una eventual expedición -como en efecto lo pensaron en 1826 y 1827. Pero incluso ante esta eventualidad, una campaña expedicionaria debía pasar también por el filtro de la Realpolitik: una aventura militar en el Caribe quedaba descartada si no contaba con una fuerza combinada de repúblicas hispanoamericanas o el respaldo o neutralidad de una gran potencia europea.

Por último, vale la pena agregar unas palabras sobre la apropiación histórica de conceptos y teorías de las Relaciones Internacionales como un camino interdisciplinario que permite enriquecer la Historia Diplomática. Estos aportes, que dan paso a una Historia de las

\footnotetext{
${ }^{126}$ Hugh Thomas, Cuba. The Pursuit of Freedom (New York: Harper and Row, 1971), 105.

${ }^{127}$ Ver, por ejemplo, los discursos de fines del siglo XIX del líder liberal Rafael Uribe, "La cuestión cubana”, en Rafael Uribe Uribe, Discursos, Cámara de Representantes (1896) (Medellín: Editorial Imp. Departamental de Antioquia), vol. 1, 1977-1978.
} 
Relaciones Internacionales más global, amplían el horizonte investigativo: no solo son importantes los "hombres de Estado", sus rasgos y preferencias, sino una estructura internacional y doméstica como factores que influyen en la formación de conductas estratégico-diplomáticas.

\section{Bibliografía}

\section{Fuentes primarias}

“Acuerdos del Consejo de Gobierno de la República de Colombia, 1821-1827”. Fundación para la Conmemoración del Bicentenario del Natalicio y el Sesquicentenario de la Muerte del General Francisco de Paula Santander. Biblioteca de la Presidencia de la República. Administración $\begin{array}{llll}\text { Virgilio } & \text { Barco. } & \text { Bogotá, }\end{array}$ http://www.bdigital.unal.edu.co/4923/31/Acuerdos_del_Consejo_de_Gobierno.html).

Archivo Santander. Diego Mendoza y Ernesto Restrepo Tirdo eds. Bogotá: Aguila Negra Editorial, 1913-32.

Archivo Sucre, t. V, Caracas, Fundación Vicente Lecuna, Banco de Venezuela, 1978.

Adams, John Quincy, Memoirs of John Quincy Adams, comprising portions of his diary from 1795 to 1848. Philadelphia, J.B. Lippincott \& Co, 1874-77.

$\begin{array}{lllll}\text { Founders } & \text { Online. } & \text { NHPRC. } & \text { The }\end{array}$ https://founders.archives.gov/documents/Madison/03-02-02-0762

Gaceta de Colombia, 1825

Hansard's Parliamentary Debates, vol. XXIV. London: T.C. Hansard, 1830. https://babel.hathitrust.org/cgi/pt?id=osu.32435072655376; view=1up;seq=7).

Manning, William, Diplomatic correspondence of the United States concerning the independence of the Latin-American nations. New York: Oxford University Press, Dept. of State, 1925.

Memorias del general O’Leary, Caracas, Imprenta de la Gaceta Oficial, 1879-1888.

Relaciones diplomáticas de Colombia y la Nueva Granada: Tratados y Convenios 1811-1856. Luis Horacio López Domínguez (Compilador). http://www.bdigital.unal.edu.co/4773/1044/Relaciones_Diplomaticas_de_Colombia_y_La_Nu eva_Granada.html.

"Santander y el Congreso de 1823. Actas y Correspondencia". Bogotá: Fundación para la Conmemoración del Bicentenario del Natalicio y el Sesquicentenario de la Muerte del General Francisco de Paula Santander. Biblioteca de la Presidencia de la República, 1989. http://www.bdigital.unal.edu.co/5628/106/Santander_y_el_Congreso_de_1823_Actas_y_Corre spondencia.htm\#s3ca). 
"Simón Bolívar: un pensamiento sobre el Congreso de Panamá, Lima, Febrero de 1826". Manuel Pérez Vila (Compilador/Editor). Doctrina del Libertador. Documento 69. Caracas: Biblioteca Ayacucho, 1985, 216-218.

Simón Bolívar. Obras completas. Compilación y notas de Vicente Lecuna, con la colaboración de la señorita Esther Barret de Nazaris. 3 vol. La Habana, 1950.

\section{Fuentes secundarias}

Art, Robert y Patrick Cronin, The United States and Coercive Diplomacy. Washington: United States Institute of Peace Press, 2003.

Blancpain, François. Un Siècle de Relations Financières entre Haïti et La France (1825-1922). Paris, Montréal: Budapest L’Harmattan, 2001.

De la Cuesta, Leonel Antonio. “Cuba y Venezuela en los primeros años bolivarianos”. Revista Hispano Cubana, 31 (2008).

De la Reza, Germán. "El intento de integración de Santo Domingo a la Gran Colombia (1821-1822)", Secuencia, no. 93, (2015), 65-82.

De la Reza, Germán. Documentos del Congreso Anfictiónico de Panamá. Caracas: Fundación Biblioteca Ayacucho y Banco Central de Venezuela, 2010.

Díaz-Callejas, Apolinar y Roberto González Arana. Colombia y Cuba: del distanciamiento a la cooperación. Bogotá: Ediciones Uninorte, 1998.

Fortique, José Rafael. El corso venezolano y las misiones de Irving y de Perry en Angostura. Maracaibo: Editorial Universitaria de la Universidad del Zulia, 1968.

Garrigó, Roque E. Historia documentada de la conspiración de los Soles y Rayos de Bolívar, 2 tomos. La Habana: Imprenta “El Siglo XX”, 1929.

Guerra y Sánchez, Ramiro. Manual de historia de Cuba: desde su descubrimiento hasta 1868. La Habana: Instituto Cubano del Libro, Editorial de Ciencias Sociales, 1971.

González, Margarita. Bolívar y la independencia de Cuba. Bogotá: El Áncora Editores, 1985.

Helg, Aline. "Simón Bolívar's Republic: a bulwark against the "Tyranny" of the Majority". Revista de Sociologia e Política, 20, 42 (2012): 21-37.

Jackson Turner, Frederick. Rise of the new West, 1819-1829. New York and London: Harper \& brothers, 1906.

“José Fernández de Madrid y su obra en Cuba”. La Habana: Publicaciones del Archivo Nacional de Cuba, 1962.

Le Riverend, Julio. "José Fernández de Madrid en Cuba: su obra”. Cuba-Colombia, una historia común. Bogotá, Editorial Universidad Nacional, 1995. 
Levy, Jack, "Deterrence and Coercive Diplomacy: The Contributions of Alexander George". Political Psychology, Vol. 29, No, 4 (2008): 537-552.

"Lucas Alamán. El reconocimiento de nuestra independencia por España y la unión de los países hispanoamericanos". Con una introducción por Antonio de la Peña y Reyes. México: Publicaciones de la Secretaria de relaciones exteriores, 1930.

Manning, William. Early diplomatic relations between the United States and Mexico. Baltimore: The Johns Hopkins Press, 1916.

Marrero Artiles, Leví. Cuba: Economía y Sociedad, vol. VII. Madrid, Editorial Playor, 1992.

Mazzar, Michael y James Goodby, "Redefining the Role of Deterrence". En Deterrence: Its Past and Future, editado por George Shultz, Sidney Drell y James Goodby. Stanford: Hoover Institution Press, 2011, 47-97.

Méndez Capote, Renée. 4 conspiraciones. La Habana: Gente Nueva, 1972.

Pérez Guzmán, Francisco. "Cuba bolivariana", Revista de la Biblioteca Nacional José Martí, Año 74, XXV, 3 (1983).

Pidival, Francisco. Bolívar. Pensamiento precursor del antiimperialismo. Cuba: Ediciones Casa de las Américas, 1977.

"Rocafuerte y quince años de Historia de la República del Ecuador", Prólogo y notas de Neptalí Zúñiga, vol. XIV. Quito: Edición del Gobierno del Ecuador. Homenaje a don Vicente Rocafuerte en el primer centenario de su muerte, 1947.

Roig de Leuchsenring, Emilio. Bolívar, el Congreso Interamericano de Panamá en 1826, y la independencia de Cuba y Puerto Rico". La Habana: Oficina del Historiador de la Ciudad, 1956.

Roldán Oquendo, Ornán. Las relaciones entre México y Colombia 1810-1862. Tlatelolco, Secretaría de Relaciones Exteriores, 1974.

Chávez Orozco, Luis (comp.). Un esfuerzo de México por la independencia de Cuba. México: Publicaciones de la Secretaria de relaciones exteriores, 1930.

Páez, José Antonio. Memorias del general José Antonio Páez: autobiografía. Madrid: Editorial América, 1916.

Pérez Guzmán, Francisco. Bolívar y la independencia de Cuba. La Habana: Editorial Letras Cubanas, 1988.

Perkins, Bradford. Castlereagh and Adams: England and the United States, 1812-1823. Berkeley: University of California Press, 1964.

Pi-Suñer Llorens, Antonia y Agustín Sánchez Andrés, Una historia de encuentros y desencuentros. México y España en el siglo XIX. México: Secretaría de Relaciones Exteriores, 2001.

Porras Troconis, Gabriel. "Bolívar y la Independencia de Cuba”. Boletín historial, 3, 32 (1917): 1-16. 
Pratts, Edgardo. "Simón Bolívar y Puerto Rico: acercamiento a una expedición”, 6 de marzo de 2019, MINH. https://minhpuertorico.org/index.php/noticias/55-noticias/7116-edgardo-pratts-claridad

Restrepo, José Manuel. Historia de la Revolución de la República de Colombia en la América Meridional. Bogotá: Imprenta Nacional, tomo VI, 1945.

Ripsman, Norrin, Jeffrey W. Taliaferro, y Steven E. Lobell, Neoclassical Realist Theory of International Politics. New York: Oxford University Press 2016.

Santovenia, Emeterio S. Armonías y conflictos en torno a Cuba. Méjico: Fondo de Cultura Económica, 1956.

Santovenia, Emeterio S. Bolívar y las Antillas hispanas. Madrid: Espasa Calpe, 1935.

Sevilla Soler, María del Rosario. Las Antillas y la independencia de la América española (1808-1826). Sevilla: Escuela de Estudios Hispanoamericanos, 1986.

Suárez, Roberto. “Colombia y Cuba, 1825-1826”. Repertorio Colombiano. XVIII, 4 (1898).

Temperley, Harold William. The foreign policy of Canning, 1822-1827; England, the neo-Holy alliance and the New World. London: G. Bell and Sons, Ltd., 1925.

Thomas, Hugh. Cuba. The Pursuit of Freedom. New York: Harper and Row, 1971.

Torres-Cuevas, Eduardo. "De la Ilustración reformista al reformismo liberal". Historia de Cuba. La Colonia. Evolución socioeconómica y formación nacional. De los orígenes hasta 1867 (La Habana, Editora Política, 1994.

Uribe Uribe, Rafael. Discursos, Cámara de Representantes (1896). Medellín: Editorial Imp. Departamental de Antioquia, vol. 1, 1977-1978.

Venegas Delgado, Hernán. La Gran Colombia, México y la independencia de las Antillas Hispanas (18201827). Hispanoamericanismo e injerencia extranjera. México: Escuela de Ciencias SocialesUniversidad Autónoma de Coahuila-Editorial Plaza y Valdés, 2010.

Venegas Delgado, Hernán. “Los planes colombo-mexicanos de expedición conjunta para la liberación de Cuba (1820-1827)". Caribbean Studies, 36, 1 (2008).

Vivanco, Julián. José Antonio Miralla. Precursor de la Independencia de Cuba. La Habana: Editorial "El Sol”, 1958.

Zubieta, Pedro Antonio. Apuntaciones sobre las primeras misiones diplomáticas de Colombia. Bogotá: Imprenta Nacional, 1924. 